\title{
HyPRP1 performs a role in negatively regulating cotton resistance to $V$. dahliae via the thickening of cell walls and ROS accumulation
}

\author{
Jun Yang, Yan Zhang, Xingfen Wang, Weiqiao Wang, Zhikun Li, Jinhua Wu, Guoning Wang, Liqiang Wu, \\ Guiyin Zhang and Zhiying $\mathrm{Ma}^{*}$
}

\begin{abstract}
Background: Developing tolerant cultivars by incorporating resistant genes is regarded as a potential strategy for controlling Verticillium wilt that causes severe losses in the yield and fiber quality of cotton.

Results: Here, we identified the gene GbHyPRP1 in Gossypium barbadense, which encodes a protein containing both proline-rich repetitive and Pollen Ole e I domains. GbHyPRP1 is located in the cell wall. The transcription of this gene mainly occurs in cotton roots and stems, and is drastically down-regulated upon infection with Verticillium dahliae. Silencing HyPRP1 dramatically enhanced cotton resistance to V. dahliae. Over-expression of HyPRP1 significantly compromised the resistance of transgenic Arabidopsis plants to $V$. dahliae. The GbHyPRP1 promoter region contained several putative phytohormone-responsive elements, of which SA was associated with gene down-regulation. We compared the mRNA expression patterns of HyPRP1-silenced plants and the control at the global level by RNA-Seq. A total of 1735 unique genes exhibited significant differential expression. Of these, 79 DEGs involved in cell wall biogenesis and 43 DEGs associated with the production of ROS were identified. Further, we observed a dramatic thickening of interfascicular fibers and vessel walls and an increase in lignin in the HyPRP1silenced cotton plants compared with the control after inoculation with $V$. dahliae. Additionally, silencing of HyPRP1 markedly enhanced ROS accumulation in the root tips of cotton inoculated with $V$. dahliae.
\end{abstract}

Conclusions: Taken together, our results suggest that HyPRP1 performs a role in the negative regulation of cotton resistance to $V$. dahliae via the thickening of cell walls and ROS accumulation.

Keywords: Cotton, Hybrid proline-rich protein (HyPRP), Verticillium dahliae, Cell wall protein, Reactive oxygen species (ROS), Virus-induced gene silencing (VIGS)

\section{Background}

The plant cell wall contains a large set of structural proteins that are involved in defense response. Cell wall proteins are unusually rich in one or two amino acids and contain highly repetitive sequence domains. Currently, much is known about their sequence information, but there is little direct evidence of the functions of these proteins [1]. Hybrid proline-rich proteins (HyPRPs) form a subgroup of putative plant cell wall glycoproteins enriched

\footnotetext{
* Correspondence: mzhy@hebau.edu.cn

North China Key Laboratory for Crop Germplasm Resources of Education

Ministry, Hebei Agricultural University, Baoding 071001, China
}

in proline. HyPRPs are composed of three different domains: a hydrophobic signal peptide, a repetitive proline-rich domain in the N-terminus, and a hydrophobic C-terminal domain, not specifically rich in proline or glycine but containing cysteine. Based on the abundance and specific distribution of cysteine in this C-terminal domain, the HyPRPs are subdivided into A and B groups. In group A, four or six cysteine residues are present in a specific pattern (-CXXC-C-C-C-C-), while group B contains eight cysteine residues (termed the eight-cysteine motif, $8 \mathrm{CM}$ ) in a specific order (-C-C-CC-CXC-C-C-) in the C-ter minal domain [2]. Multiple studies have indicated that

(c) The Author(s). 2018 Open Access This article is distributed under the terms of the Creative Commons Attribution 4.0 International License (http://creativecommons.org/licenses/by/4.0/), which permits unrestricted use, distribution, and 
group B HyPRPs play various functional roles in specific developmental stages and in response to biotic and abiotic stresses. For example, CaHyPRP1 performs distinct dual roles as a negative regulator of basal defense and in the positive regulation of cell death in Capsicum annuum against Xanthomonas campestris [3]. GmHyPRP is involved in triggering the soybean resistance response to Phakopsora pachyrhizi [4]. The HyPRP gene EARLI1 (Early Arabidopsis Aluminum Induced 1) is induced in Arabidopsis by low temperature and salt stress [5]. GhHyPRP4 has been reported to take part in the cold stress response of Gossypium hirsutum [6]. Overexpression of CCHyPRP from Cajanus cajan increased resistance to multiple abiotic stresses in yeast and Arabidopsis [7]. However, the roles of group A HyPRPs in plant development and defense against pathogen attacks remain unclear, in contrast to the relatively better characterized proteins of group B. As of now, only one group A protein, PvPRP1, has been researched extensively. PvPRP1 can be down-reglated by Colletotrichum lindemuthianum and up-regulated by wounding in the hypocotyls of French bean (Phaseolus vulgaris) [8]. The down-regulated expression of PvPRP1 in response to fungal infection is due to mRNA destabilization through the binding of PRP-BP (PvPRP1 mRNA binding protein) to a 27-nucleotide U-rich domain in the $3^{\prime}$ untranslated region of $P v$ PRP1 mRNA [9].

Verticillium dahliae Kleb is a soil-borne pathogenic fungus capable of causing vascular wilt disease in cotton (Gossypium spp.). In most cotton-growing areas, Verticillium wilt has become the most important disease of cotton [10]. Unfortunately, currently available fungicides are not effective in protecting cotton from this vascular disease infection. Therefore, developing tolerant cotton cultivars by incorporating genes from resistant germplasm is now regarded as the most effective strategy for controlling this disease. Genetic dissection of Verticillium wilt resistance at the molecular level, as mediated by the relevant genes, will enhance our ability to utilize the existing germplasm to reduce cotton yield losses [11].

In recent years, high-throughput technology has been used to systematically monitor expression profiles and screen a wide spectrum of differentially expressed genes/ proteins in cotton inoculated with $V$. dahliae with the goal of ultimately using genetic engineering to breed resistant cultivars. A total of 188 differentially expressed proteins were identified in the roots of Gossypium barbadense upon infection with $V$. dahliae based on comparative proteomics analysis [12]. Moreover, 3442 unigenes related to defense responses against $V$. dahliae were identified in G. barbadense cv. 7124 using RNA-Seq [13]. In addition, a total of 3027 Veticillium-resistance unigenes were identified from a full-length cDNA library of G. barbadense cv Pima90-53 [14]. These compre hensive gene and protein expression data provide helpful molecular information. However, deeper insights into understanding the defense mechanisms of cotton in response to $V$. dahliae are needed.

Previously, we obtained a substantial number of transcript sequences from $G$. barbadense related to defense responses against $V$. dahliae [14]. Of these, a cDNA clone that encodes a group A HyPRP protein, designated as GbHyPRP1, whose expression was significantly downregulated in cotton after $V$. dahliae inoculation. In the present study, GbHyPRP1 and its homologous genes were cloned from other $G$. hirsutum cultivars. The transcriptional expression of HyPRP1 was investigated in different tissues and in response to treatment with different hormones and $V$. dahliae. A potential role of HyPRP1 in negatively regulating plant resistance to $V$. dahliae was examined by overexpression in Arabidopsis and by virus-induced gene silencing (VIGS) in cotton. We applied transcriptomic analysis to systematacially explore the molecular mechanisms underlying the HyPRP1-mediated cotton defensive response to $V$. dahliae. The important function of HyPRP1 involved in cotton resistance to $V$. dahliae via the thickening of the cell wall and ROS accumulation was proved.

\section{Results \\ GbHyPRP1 is a cell wall protein down-regulated by $V$. dahliae challenge}

Previously, we isolated a full-length cDNA clone from a full-length cDNA library of G. barbadense Pima90-53 challenged with $V$. dahliae [14]. The cDNA clone has a $5^{\prime}$ untranslated region (5' UTR) of $41 \mathrm{bp}, 3^{\prime}$ UTR of $186 \mathrm{bp}$ with a polyA tail and an open reading frame (ORF) of $945 \mathrm{bp}$ that potentially encodes a 314-amino acid protein. The protein consists of a 26-residue signal peptide (SP) sequence with an initial ATG codon, a 165-residue proline-rich domain (PRD) (containing a basic histidine-rich domain) at the $\mathrm{N}$-terminus and a 123-residue hydrophobic C-terminus Pollen Ole e I domain (cysteine-containing domain) (Fig. 1a). Based on the sequence features and a homology search, the protein belongs to group A HyPRPs, designated as GbHy PRP1 (GenBank accession number KP162172). Gb HyPRP1 has a predicted molecular weight of $\sim 33.59$ $\mathrm{kDa}$ with a theoretical pI of 9.97. The alignment results showed that GbHyPRP1 from G. barbadense shared a high sequence identity with the other GhHyPRP1 proteins from six cultivars of G. hirsutum (Additional file 1: Figure S1).

A GFP gene fused to the C-terminal end of GbHyPRP1 under the control of the constitutive CaMV $35 \mathrm{~S}$ promoter was successfully transformed into tobacco epidermal cells and transiently expressed. The control GFPs appeared to be distributed throughout the whole cell, 


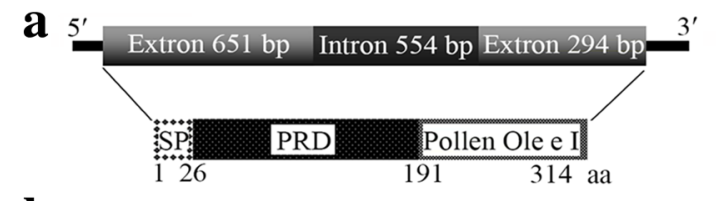

b

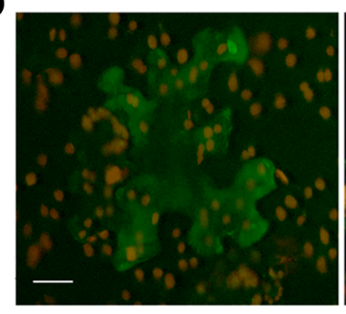

GFP

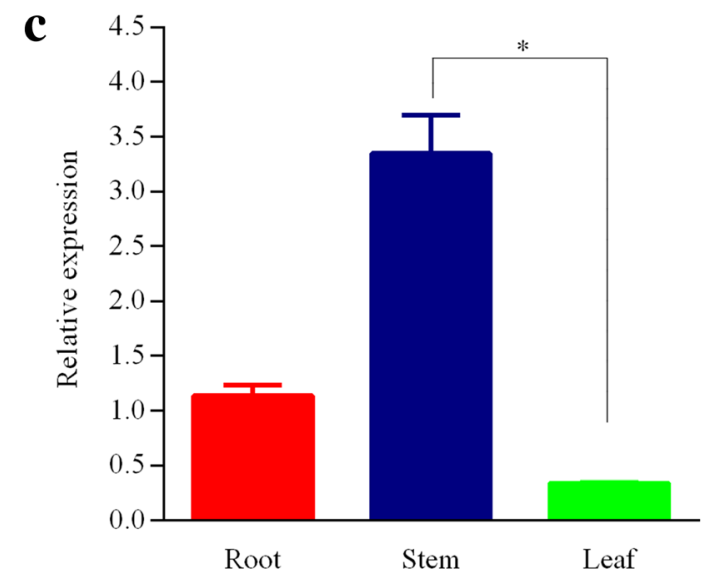

d
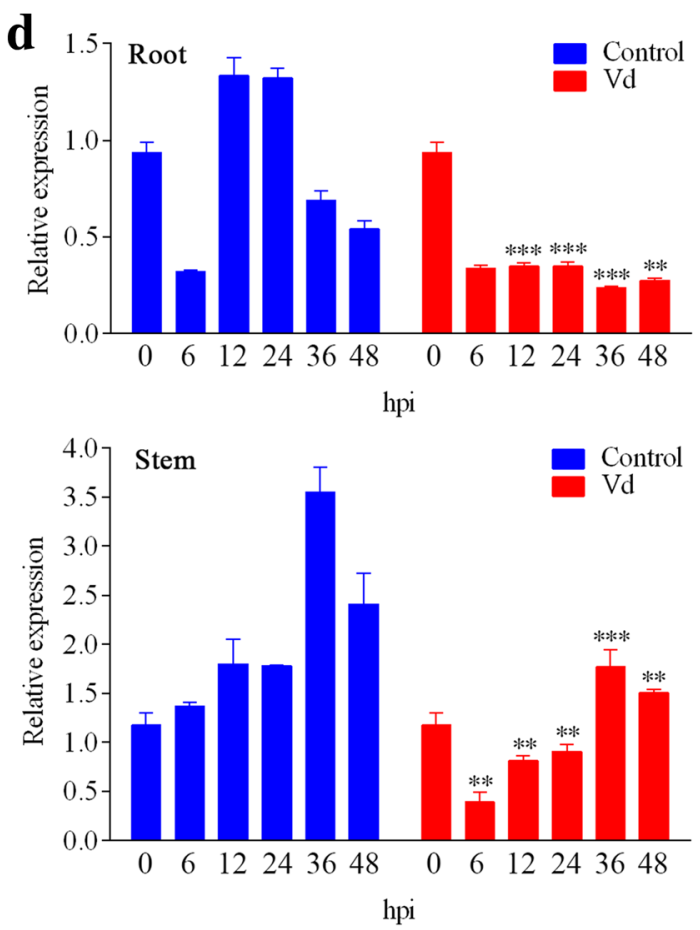

Fig. 1 Characterization of GbHyPRP1. a Schematic structure of GbHyPRP1. b Subcellular localization of GFP alone or GbHyPRP1-GFP fusion in tobacco leaves transiently transformed by Agrobacterium infiltration. The green fluorescence were monitored using a confocal laser scanning microscope. Bars $=10 \mu \mathrm{m}$. c Tissue-specific expression of GbHyPRP1 by qPCR. Two-week-old G. barbadense Pima90-53 plants were used for sampling. The values were normalized to gene PP2A1. The significant differences in expression level of GbHyPRP1 in different tissues were evaluated by the non-parametric Kruskal-Wallis test followed by Dunn's multiple comparisons test. The bar represents mean \pm SE from three biological replicates $(* P<0.05)$. $\mathbf{d}$ Transcriptional analysis of GbHyPRP1 were measured in response to $V$. dahliae $(\mathrm{Vd})$ compared to the control by $\mathrm{qPCR}$. The roots and stems of two-week-old Vd-exposed Pima90-53 seedlings and control (water-treated) were collected. The values were normalized to gene PP2A1. The bar represents mean \pm SE from three biological replicates. Sidak's multiple comparisons test demonstrated that there were significant differences ( ${ }^{* *} P<0.01,{ }^{* * *} P<0.001$ ) between $\mathrm{Vd}$ and control at $0,6,12,24,36$ and $48 \mathrm{~h}$ post-inoculation (hpi)

which indicated that GFPs were localized to plasma membrane and cytoplasm. By contrast, the GFP signal indicated that the fusion HyPRP1-GFP proteins were localized to the cell periphery (Fig. 1b). In addition, GbHyPRP1 belongs to group A HyPRPs (Fig. 1a), which form a subgroup of plant cell wall glycoproteins enriched in proline. Thus, we inferred that HyPRP1 localized to the cell wall.

As shown in Fig. 1c, GbHyPRP1 was expressed in all tested parts of the cotton plants, with a significantly higher expression level in the stem compared with the leaf. In addition, the expression profiles of GbHyPRP1 in response to the highly aggressive defoliating $V$. dahliae strain were examined in infected G. barbadense roots and stems. The qPCR (real-time quantitative PCR) analysis showed that the expression level of GbHyPRP1 significantly decreased in either stems or roots after inoculation with $V$. dahliae (Fig. 1d). These data indicate that GbHyPRP1 is involved in the cotton- $V$. dahliae interaction.

\section{V. dahliae-responsive expression of HyPRP1 exhibits the same trend in G. hirsutum as in G. barbadense}

We further determined the $V$. dahliae-responsive expression of HyPRP1 in G. hirsutum using a resistant cv. ND601(DI $=22.63 \pm 2.28)$ and a susceptible cv. CCRI8 (DI $=57.59 \pm 2.76$ ) [15] inoculated with $V$. dahliae (Fig. 2)a. The results showed that the expression of HyPRP1 dramatically decreased in both resistant and susceptible cotton stems and roots after inoculation with $V$. dahliae compared to the control (Fig. 2b). Moreover, the expression of HyPRP1 in the resistant cv. ND601 was significantly lower compared to the susceptible cv. CCRI8 (Fig. 2b). These results ulteriorly indicated that HyPRP1 is a negative regulator involved in the cotton- $V$. dahliae interaction. 

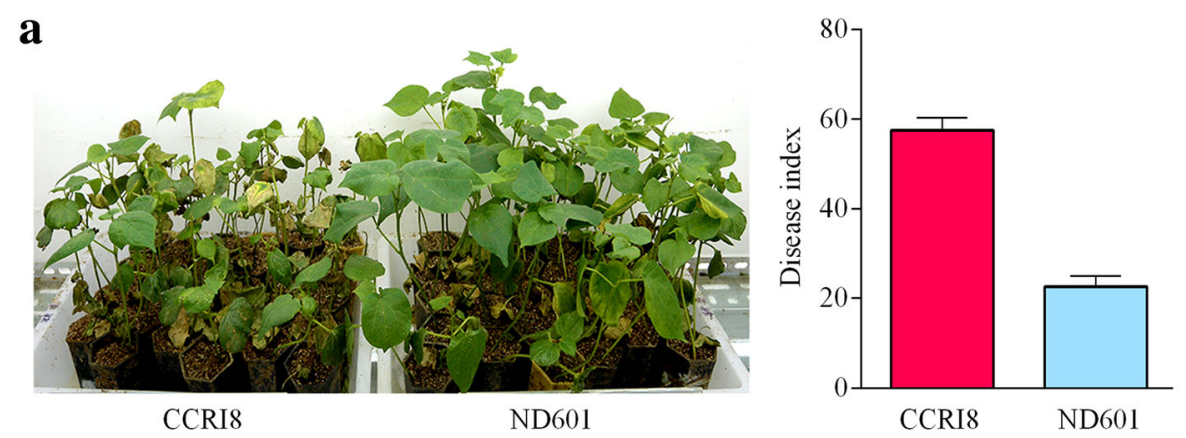

b

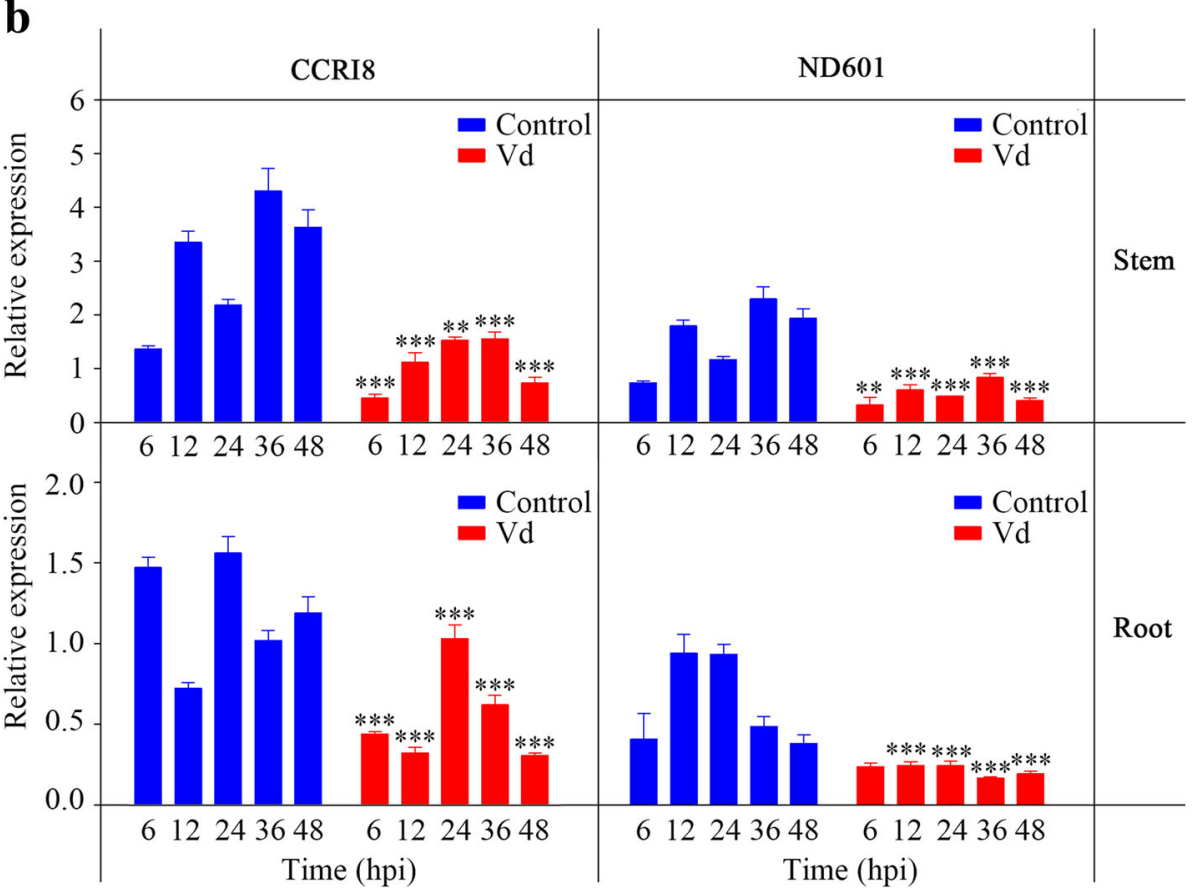

Fig. 2 Time-related changes in the expression of HyPRP1 in response to V. dahliae (Vd) in G. hirsutum.a ND601 showed higher tolerence to V. dahliae (left panel) with lower disease index (right panel) compared to CCRI8 at $14 \mathrm{dpi}$. Two-week-old seedlings were dip-infected with the $V$. dahliae spores. The disease indices were presented means \pm SE from three biological replications with at least 15 plants per replication. $\mathbf{b}$, The expression of HyPRP1 changed to a lower degree both in stems and roots of tolerent ND601 and susceptible CCRI8 after infection using V. dahliae comparing to the control at the same hpi. Meanwhile, the relative expression of HyPRP1 displayed more lower both in stems and roots of tolerent ND601 comparing to the susceptible CCRI8 after infection using V. dahliae at the same hpi. The relative gene expression was calculated using the comparative $2^{-\triangle \triangle C t}$ method with PP2A1 as endogenous control gene. Values are shown as the mean \pm SE of three biological replicates. Sidak's multiple comparisons test demonstrated that there were significant differences $\left.{ }^{* *} P<0.01,{ }^{* *} P<0.001\right)$ between $V d$ and control

\section{Silencing of HyPRP1 enhances cotton resistance to Verticillium wilt}

We further tested whether $H y P R P 1$ was required for cotton resistance to Verticillium wilt using VIGS, which is frequently employed as a reverse genetics technique. At approximately two weeks post-infiltration, marker gene CLA1-VIGS plants started to display the albino phenotype in the true leaves (Additional file 2: Figure S2A). At the same time, the expression of HyPRP1 in susceptible CCRI8 was not detected using semi-RT-PCR, indicating that $H y P R P 1$ had been silenced (Additional file 2: Figure S2B). HyPRP1-silenced plants were used for Verticillium inoculation. At 15 days post inoculation (dpi), less chlorosis and fewer wilting leaves were observed in VIGS plants compared to the control (Fig. 3a). The DI of VIGS plants $(32.67 \pm 1.96)$ was significantly lower than that of the control $(81.00 \pm 2.13)$, i.e., susceptible CCRI8 became tolerent (Fig. 3b). VIGS assays indicated that silencing of HyPRP1 significantly enhances cotton resistance to Verticillium wilt.

Over-expression of GbHyPRP1 compromises Arabidopsis resistance to Verticillium wilt

To further determine the involvement of GbHyPRP1 in Verticillium wilt resistance, plant over-expression vectors containing the GbHyPRP1 ORF driven by a constitutive 

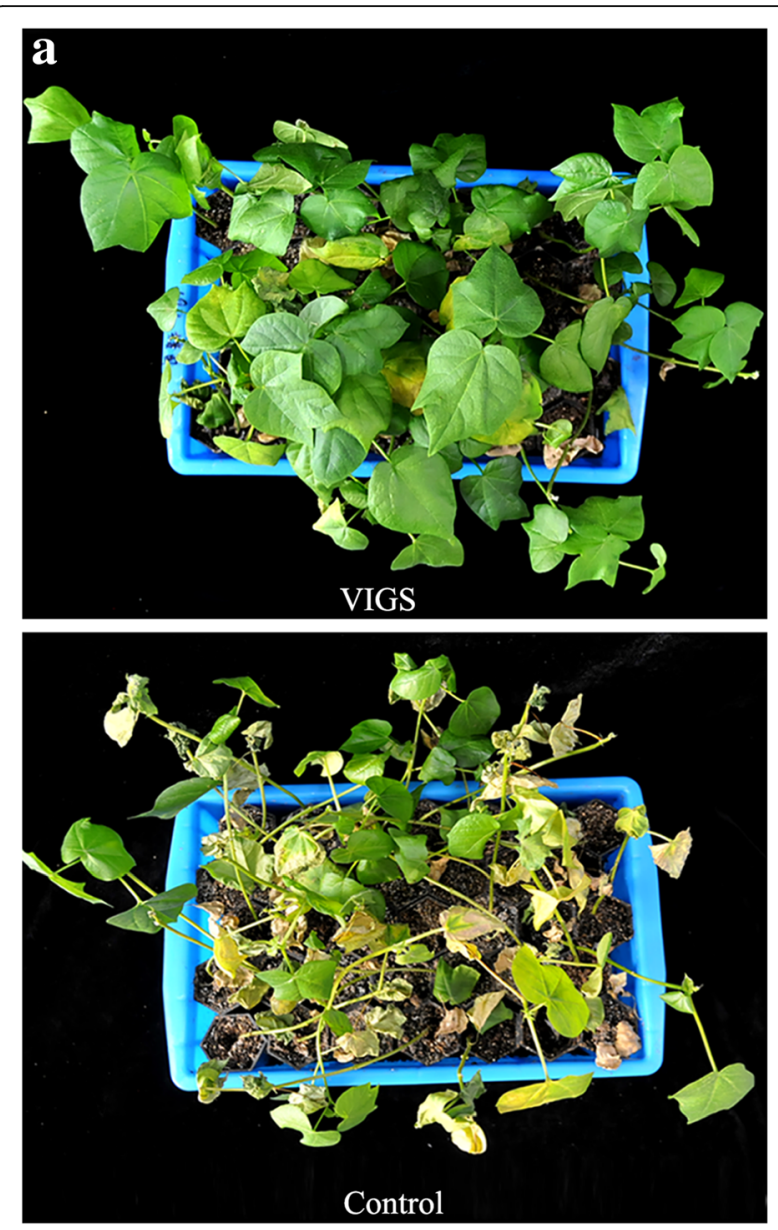

b

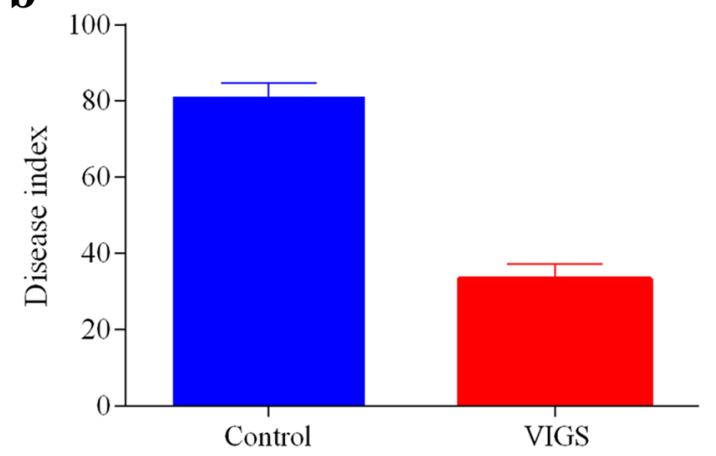

Fig. 3 Silencing of HyPRP1 enhanced cotton plant resistance to Verticillium wilt. a Disease symptoms of HyPRPT VIGS CCRI8 plants after inoculation with $V$. dahliae strain Linxi2-1. Control plants were infiltrated with Agrobacterium carrying a VIGS empty vector. Photographs were taken at $15 \mathrm{dpi}$. b The disease index was measured at 15 dpi. Error bars represent SE of three biological replicates with at least 35 plants per replication

$35 \mathrm{~S}$ promoter were constructed and transformed (Agrobacterium-mediated) into Arabidopsis thaliana. Three lines, L1, L2 and L3, were used for further analyses. After 15 dpi with $V$. dahliae, all the transgenic lines exhibited more wilting and etiolation compared to WT (wild type)
(Fig. 4a). The average DI of transgenic plants, i.e., 69.5 (classifed as susceptable), was significantly higher than that of the control (29.8; classified as tolerant) (Fig. 4b). These results suggest that over-expression of GbHyPRP1 compromised Arabidopsis resistance to Verticillium wilt.

\section{GbHyPRP1 contains hormone elements in the promoter and is down-regulated by SA}

The upstream region of GbHyPRP1, named pGbHyPRP1, was $1431 \mathrm{bp}$ in length based on sequencing (Additional file 3: Figure S3). pGbHyPRP1 fused with the reporter gene GUS introduced into Arabidopsis plants, and GUS staining confirmed that the promoter of GbHyPRP1 functioned well with respect to the expression of the reporter gene (Fig. 5a). Promoter search using PLANTCARE indicated that several potentially inducible cis-regulatory elements corresponding to hormone, defense and pathogen elicitor responses were found in pGbHyPRP1 (Fig. 5b). Thus, we investigated the expression profile of GbHyPRP1 following treatments with plant hormones, including SA (salicylic acid), abscisic acid (ABA), jasmonic acid (JA) and ethylene (ET). The results indicated that the expression of GbHyPRP1 was strongly down-regulated by SA at 12, 24, 36 and 48 hps (hours post-spraying), whereas it was significantly up-regulated by ABA, JA and ET at various time points (Fig. 5c). To our surprise, the $H y P R P 1$ transcript levels in the SA-treated plants were quite similar to those in the $V$. dahliae-inoculated cotton seedlings (Figs. 1d and 2b). These results imply that HyPRP1 may play roles in cotton resistance to $V$. dahliae through the SA-mediated signaling pathway.

Transcriptome analysis of VIGS cotton indicated HyPRP1 influences genes related to cell wall remodeling and ROS balance

To better understand the molecular mechanisms of HyPRP1-mediated cotton defense response to $V$. dahliae, we empoyed a combined approach of VIGS and RNA-Seq to compare the mRNA expression patterns of HyPRP1-silenced and control plants at the global level. Transcriptome libraries yielded $56,364,572$ to $63,092,290$ raw reads. After cleaning and quality checks, 55,741,348 to $62,384,322$ high quality reads were obtained, and $79.66-80.87 \%$ of these reads were uniquely mapped to G. hirsutum L. acc. TM-1 [16], representing more than forty thousand unigenes(RPKM $\geq 1)$ (Table 1$)$. Under $V$. dahliae stress, a total of 1735 unique genes exhibited significant differential expression based on VIGS compared to the control, including 816 up-regulated and 919 down-regulated genes $(P$-value $\leq 0.05)$ (Additional file 4: Data S1).

Of these, we identified 79 differentially expressed genes (DEGs) that might be involved in cell wall 
$\mathbf{a}$

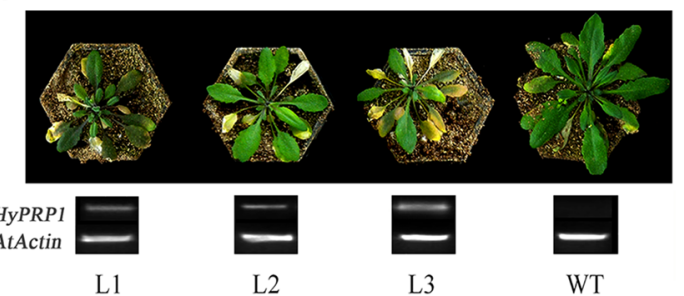

b

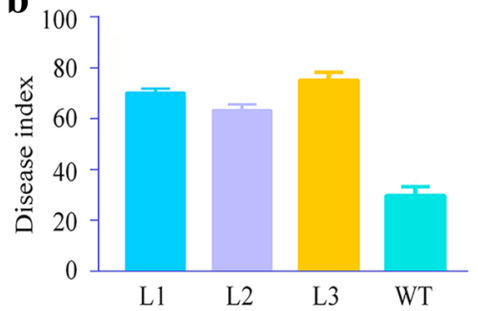

Fig. 4 Over-expression of GbHyPRP1 compromised Arabidopsis resistance to Verticillium wilt. a Phenotype comparison of transgenic lines (L1, L2 and L3) and the WT inoculated with V. dahliae. Photographs were taken at 15 dpi. Expression of GbHyPRP1 was confirmed using semi-qRT-PCR. The AtActin gene was used as a control. $\mathbf{b}$ The disease index was measured at $15 \mathrm{dpi}$. Error bars represent the SE of three biological replicates with at least 20 plants per replication

biogenesis in cotton according to the annotation from the cell wall genomics webserver (https://cellwall.genomics.purdue.edu/intro/index.html) (Table 2). Expansins and xyloglucan-modifying enzymes are usually up-regulated by various stresses and then become involved in cell wall remodeling [17]. Our RNA-Seq results indicated that the expression of six expansin genes (Gh_A10G1374, Gh_A05G2385, Gh_A05G3493, Gh_A1
3G0050, Gh_D04G1924 and Gh_D05G2650) and seven xyloglucan endotransglucosylase/hydrolase $(\mathrm{XEH})$ genes (Gh_A02G1426, Gh_A11G1910, Gh_D03G0294, Gh_D1 1G2065, Gh_A11G0455, Gh_D05G1444 and Gh_D02G1 $371)$ were significantly up-regulated in $H y P R P 1$ VIGS cotton seedlings inoculated with $V$. dahliae compared to the control. Additionally, reactive oxygen species (ROS) have been shown to be associated with cotton a

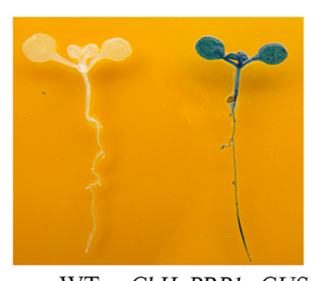

WT $p G b H y P R P 1:: G U S$

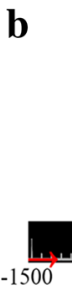

1500

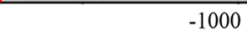

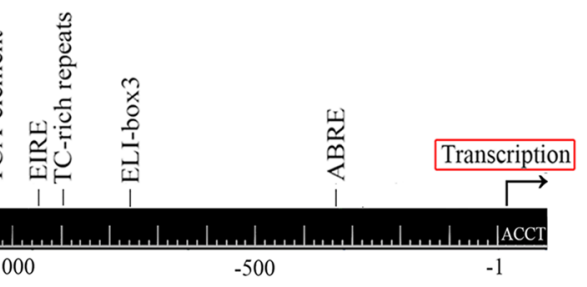

C

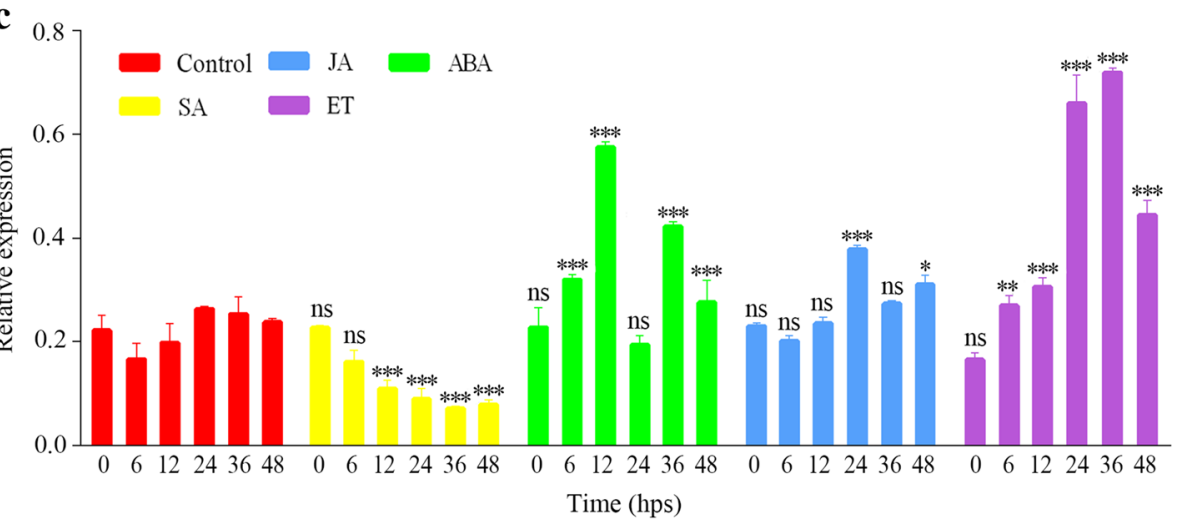

Fig. 5 Properties of pGbHyPRP1. a Histochemical analysis of GUS activity in Arabidopsis expressing the pGbHyPRP1-GUS chimeric gene. GUS activity was present in whole 7-day-old seedlings. $\mathbf{b}$ Location of cis-regulatory elements involved in hormone- and elicitor-responsive elements found in PGbHyPRP1. The conserved fungus-responsive elements ELI-box3 (-216) were present in the promoter region of WRKY in the Populus, while the EIRE (elicitor responsive element) (-879) are the binding site of WRKY and required for elicitor responsiveness in the promoter of PR (pathogenesis-related protein) in the parsley $[64,65]$. TC-rich repeat elements $(-502)$ are putatively involved in plant defense and stress response. Furthermore, ABRE (ABA-responsive element) (-292), TCA-element and ERE (ethylene responsive element) (- 1128) have been reported in the upstream region of many genes that show regulated expression in response to ABA, SA and Et, respectively [26-28]. c Expression profiles of GbHyPRP1 in leaves of 15-day-old Pima90-53 seedlings subjected to SA, ABA, JA and ET. Control indicates water treatment. Three plants at each time point were sampled and analysed. Values are presented as the means \pm SE in three independent experiments. Asterisks represent significant differences with respect to the control as determined by Tukey's multiple comparisons test ${ }^{*} P<0.05,{ }^{* *} P<0.01$; ${ }^{* * *} P<0.001$;

ns = not significant) 
Table 1 Summary of sequencing, read processing, mapping, and differential expression analysis

\begin{tabular}{|c|c|c|c|c|}
\hline \multirow{2}{*}{$\begin{array}{l}\text { Sample names \& } \\
\text { Replicates }\end{array}$} & \multicolumn{2}{|l|}{ Control-12 hpi (C12) } & \multicolumn{2}{|l|}{ VIGS-12 hpi (V12) } \\
\hline & C12-1 & C12-2 & V12-1 & V12-2 \\
\hline Raw reads & $60,758,592$ & $56,364,572$ & $59,201,676$ & $63,092,290$ \\
\hline Clean reads & $60,228,094$ & $55,741,348$ & $58,628,694$ & $62,384,322$ \\
\hline Q20 (\%) & 96.12 & 96.11 & 96.13 & 96.20 \\
\hline Q30 (\%) & 92.44 & 92.49 & 92.46 & 92.58 \\
\hline GC content $(\%)$ & 44.62 & 43.65 & 45.03 & 45.34 \\
\hline Total mapped & $56,294,373(93.47 \%)$ & $51,961,420(93.22 \%)$ & $54,610,037$ (93.15\%) & $58,335,113(93.51 \%)$ \\
\hline Uniquely mapped & $48,617,647$ (80.72\%) & $45,077,574(80.87 \%)$ & $46,702,784(79.66 \%)$ & 49,786,940 (79.81\%) \\
\hline Detected genes(RPKM $\geq 1)$ & 46,067 & 46,695 & 42,211 & 43,636 \\
\hline
\end{tabular}

resistance to fungal pathogens [18]. Here, we found 43 DEGs associated with the production and scavenging of $\mathrm{H}_{2} \mathrm{O}_{2}$ and $\mathrm{O}_{2}^{-}$, which allows regulation of dynamic changes in ROS levels (Table 3 ). Thus, our results suggest that HyPRP1 as a cell wall structural protein might have a potential role in cotton resistance to $V$. dahliae infection through remodeling of the cotton cell wall and ROS production.

\section{Silencing of HyPRP1 causes a drastic increase in cell wall thickness and the lignin content}

To further determine the effect of silenced HyPRP1 on the cell wall, the cotton stems were histologically examined. 10-day-old seedlings with two fully expanded cotyledons were used for VIGS. After two weeks later HyPRP1-silenced plants were inoculated with $V$. dahliae. At $14 \mathrm{dpi}$, cross sections of the basal part of stems revealed that the thickness of interfascicular fiber walls increased obviously in the HyPRP1-silenced plants compared with the control (Fig. 6a and $\mathrm{a}^{\prime}$ ). Moreover, we examined vessel walls in ultra-thin sections using transmission electron microscopy, which revealed a dramatic reduction in thickness (Fig. $6 \mathrm{~b}$ and $\mathrm{b}^{\prime}$ ). These results demonstrated that silencing of HyPRP1 does not affect the development of the cell wall under a pathogen-free condition, but repression of $H y P R P 1$ expression significantly enhances cell wall thickening in response to $V$. dahliae. Further, lignin contents were estimated in cell wall residues. The data showed that HyPRP1-silenced plants had higher lignin content compared with the control at $0 \mathrm{dpi}, 7 \mathrm{dpi}$ and $14 \mathrm{dpi}$ (Fig. $7 \mathrm{a}-\mathrm{c}$ ). Accordingly, the autofluorescence of lignified cell walls in the xylem and vascular bundles of HyPRP1-silenced plants was more intense and covered a greater area compared with the control (Fig. 7d-i).

\section{Silencing of HyPRP1 enhanced ROS accumulation in root tips of cotton infected with $V$. dahliae}

We evaluated whether HyPRP1 silencing would result in cotton generating more ROS in response to $V$. dahliae infection. DAB and NBT staining showed that HyPRP1 VIGS cotton had significantly higher levels of $\mathrm{O}_{2}{ }^{-}$and $\mathrm{H}_{2} \mathrm{O}_{2}$ compared to the control under $V$. dahliae infection (Fig. 8a and b). In particular, VIGS plants not only showed darker staining approximately one millimeter from the tip, but staining was also detected in the upper part of the root (Fig. 8a and b). DCFH-DA staining further confirmed enhanced ROS levels in HyPRP1 VIGS cotton roots compared to the control (Fig. 8c). These results suggest that HyPRP1 is involved in ROS production in cotton infected with V. dahliae.

\section{Discussion}

\section{HYPRP1 is a negative regulator in cotton resistance to}

\section{Verticillium wilt}

The roles of HyPRPs in response to multiple abiotic and biotic factors such as cold, salinity, drought and pathogens have been inferred primarily from their expression profiles [3, 8, 19-22]. Remarkably, all of these HyPRP genes have been reported to be up-regulated by abiotic factors and down-regulated upon infection with pathogens, e.g., HyPRP1 in $C$. annuum and $N$. benthamiana following $P$. capsici infection [3] and PvPRP1 in cell cultures of P. vulgaris treated with an elicitor [8]. Similarly, in our study, transcriptional suppression of HyPRP1 in roots of both resistant and susceptible cotton was also detected after $V$. dahliae infection (Figs. $1 \mathrm{~d}$ and $2 \mathrm{~b}$ ). This indicates that HyPRP1 is involved in the interaction between cotton and Verticillium. Further, based on loss- and gain- of function studies comprising VIGS and over-expression in cotton and Arabidopsis plants, respectively, we showed that HyPRP1 was negatively correlated with resistance to $V$. dahliae (Figs. 3 and 4). Thus, it is reasonable to speculate that HyPRP1 functions in the process of cotton resistance to Verticillium wilt as an important negative regulator. 
Table 2 DEGs involving in cell wall biogenesis according to the annotation from the cell wall genomics webserver

\begin{tabular}{|c|c|c|c|c|c|c|}
\hline Stages of cell wall biogenesis & Gene & Cotton ID & $\begin{array}{l}\text { Arabidopsis } \\
\text { ID }\end{array}$ & Biological process description & $\log 2 \mathrm{FC}$ & padj \\
\hline \multirow[t]{5}{*}{ 1. Pathways of substrate generation } & MPG & Gh_D13G1445 & AT4G26850 & Mannose-1-phosphate guanyly|transferase & 1.3226 & 0.00074702 \\
\hline & MPG & Gh_A04G0114 & AT4G26850 & Mannose-2-phosphate guanyly|transferase & 1.0154 & 0.0038664 \\
\hline & MPG & Gh_D05G3607 & AT4G26850 & Mannose-3-phosphate guanyly|transferase & 0.87197 & 0.016364 \\
\hline & PAL2 & Gh_D06G0758 & AT3G53260 & Phenylalanine ammonia-lyase 2 & -4.7679 & 0.031477 \\
\hline & COMT & Gh_D08G2702 & AT5G54160 & O-methyltransferase 1 & -2.1454 & $1.04 \mathrm{E}-05$ \\
\hline \multirow{8}{*}{$\begin{array}{l}\text { 2. Polysaccharide synthases and } \\
\text { glycosyl transferases }\end{array}$} & CSLD5 & Gh_D12G1289 & \multirow[t]{2}{*}{ AT1G02730 } & \multirow[t]{2}{*}{ Cellulose synthase-like D5 } & -1.8163 & 4.86E-06 \\
\hline & CSLD5 & Gh_A12G1169 & & & -1.7886 & 0.00023721 \\
\hline & CSA2 & Gh_D05G2313 & AT4G39350 & Cellulose synthase A2 & 0.94515 & 0.0088594 \\
\hline & UGT & Gh_A01G1073 & AT5G65550 & \multirow{2}{*}{$\begin{array}{l}\text { UDP-Glycosyltransferase superfamily } \\
\text { protein }\end{array}$} & -1.0906 & 0.0034716 \\
\hline & UGT & Gh_A08G0702 & AT5G12890 & & 1.3521 & 0.0044964 \\
\hline & UGT2 & Gh_D02G0230 & AT1G05530 & UDP-glucosyl transferase 75B2 & 1.7995 & 0.04585 \\
\hline & UGT & Gh_A12G0455 & AT3G21780 & UDP-glucosyl transferase 71B6 & 1.1842 & 0.026133 \\
\hline & GT35 & Gh_A13G0714 & AT3G29320 & Glycosyl transferase, family 35 & -1.4741 & 0.0049557 \\
\hline \multirow{15}{*}{$\begin{array}{l}\text { 3. Secretion and targeting } \\
\text { pathways }\end{array}$} & DJC24 & Gh_A11G1350 & AT4G12780 & \multirow[t]{2}{*}{ DNA J protein C24 } & 0.93104 & 0.032233 \\
\hline & DJC24 & Gh_D03G0085 & AT2G17880 & & 0.83759 & 0.036168 \\
\hline & DJC75 & Gh_D05G2948 & \multirow[t]{2}{*}{ AT4G09350 } & \multirow[t]{2}{*}{ DNA J protein C75 } & 1.28 & 0.00014472 \\
\hline & DJC75 & Gh_A05G2646 & & & 1.3309 & 0.00072978 \\
\hline & DNJ & Gh_D11G2787 & \multirow[t]{4}{*}{ AT1G56300 } & \multirow{4}{*}{$\begin{array}{l}\text { Chaperone DnaJ-domain superfamily } \\
\text { protein }\end{array}$} & -2.2389 & $1.13 \mathrm{E}-09$ \\
\hline & DNJ & Gh_D12G1290 & & & 0.84609 & 0.048095 \\
\hline & DNJ & Gh_A11G2469 & & & -2.4022 & $2.03 \mathrm{E}-10$ \\
\hline & DNJ & Gh_A12G1170 & & & 1.2513 & 0.00021456 \\
\hline & CML12 & Gh_Sca058336G01 & \multirow[t]{3}{*}{ AT2G41100 } & \multirow[t]{3}{*}{ Calmodulin-like 12} & 1.1651 & 0.00085002 \\
\hline & CML12 & Gh_A05G1998 & & & 0.97104 & 0.03541 \\
\hline & CML12 & Gh_D07G0377 & & & 0.9888 & 0.0122 \\
\hline & CML30 & Gh_A11G3105 & AT2G15680 & Calmodulin-like 30 & 0.90289 & 0.019411 \\
\hline & $\mathrm{CaBP}$ & Gh_D01G1024 & \multirow{3}{*}{$\begin{array}{l}\text { AT1G73630 } \\
\text { AT1G21550 }\end{array}$} & \multirow[t]{3}{*}{ Calcium-binding EF-hand family protein } & 1.1131 & 0.033647 \\
\hline & $\mathrm{CaBP}$ & Gh_D05G2265 & & & 1.1609 & 0.00045229 \\
\hline & $\mathrm{CaBP}$ & Gh_A05G2022 & & & 1.0194 & 0.02553 \\
\hline \multirow{14}{*}{$\begin{array}{l}\text { 4. Assembly, architecture, and } \\
\text { growth }\end{array}$} & EXP5 & Gh_A10G1374 & AT3G29030 & Expansin A5 & 1.0678 & 0.015918 \\
\hline & EXP8 & Gh_A05G2385 & \multirow[t]{5}{*}{ AT2G40610 } & \multirow[t]{5}{*}{ Expansin A8 } & 1.1376 & 0.00071198 \\
\hline & EXP8 & Gh_A05G3493 & & & 1.2031 & 0.00047444 \\
\hline & EXP8 & Gh_A13G0050 & & & 1.0126 & 0.020419 \\
\hline & EXP8 & Gh_D04G1924 & & & 1.0878 & 0.0013803 \\
\hline & EXP8 & Gh_D05G2650 & & & 1.1075 & 0.0011793 \\
\hline & EXP11 & Gh_A05G1576 & AT1G20190 & Expansin A11 & -1.5462 & 0.00073074 \\
\hline & XTH6 & Gh_A02G1426 & \multirow[t]{4}{*}{ AT5G65730 } & \multirow{4}{*}{$\begin{array}{l}\text { Xyloglucan endotransglucosylase/hydrolase } \\
6\end{array}$} & 1.0514 & 0.0026916 \\
\hline & XTH6 & Gh_A11G1910 & & & 1.7179 & 0.0045263 \\
\hline & XTH6 & Gh_D03G0294 & & & 1.3393 & 0.0049521 \\
\hline & XTH6 & Gh_D11G2065 & & & 1.3826 & $4.78 \mathrm{E}-05$ \\
\hline & XTH7 & Gh_A11G0455 & AT4G37800 & $\begin{array}{l}\text { Xyloglucan endotransglucosylase/hydrolase } \\
7\end{array}$ & 1.0837 & 0.025074 \\
\hline & XTH16 & Gh_D05G1444 & AT3G23730 & $\begin{array}{l}\text { Xyloglucan endotransglucosylase/hydrolase } \\
16\end{array}$ & 1.0522 & 0.022367 \\
\hline & $\mathrm{XTH} 28$ & Gh_D02G1371 & AT1G14720 & Xyloglucan endotransglucosylase/hydrolase & 0.96782 & 0.021935 \\
\hline
\end{tabular}


Table 2 DEGs involving in cell wall biogenesis according to the annotation from the cell wall genomics webserver (Continued)

\begin{tabular}{|c|c|c|c|c|c|c|}
\hline Stages of cell wall biogenesis & Gene & Cotton ID & $\begin{array}{l}\text { Arabidopsis } \\
\text { ID }\end{array}$ & Biological process description & $\log 2 \mathrm{FC}$ & padj \\
\hline & & & & \multicolumn{3}{|l|}{28} \\
\hline & $\mathrm{GH} 17$ & Gh_A01G0299 & \multirow[t]{3}{*}{ AT2G39640 } & \multirow[t]{3}{*}{ Glycosyl hydrolase family 17 protein } & -2.7529 & 0.0037067 \\
\hline & $\mathrm{GH} 17$ & Gh_A05G0191 & & & -1.5162 & 0.0061888 \\
\hline & $\mathrm{GH} 17$ & Gh_Sca016465G01 & & & -1.5804 & 0.023458 \\
\hline & GH9B13 & Gh_D03G0779 & AT4G02290 & Glycosyl hydrolase 9B13 & -1.7925 & 0.0030996 \\
\hline & $\mathrm{GH} 32$ & Gh_A06G0779 & AT3G13790 & Glycosyl hydrolases family 32 protein & -1.6456 & 0.011594 \\
\hline & BG3 & Gh_D06G2277 & AT3G57240 & Beta-1,3-glucanase 3 & -2.4743 & 0.041623 \\
\hline & PLL & Gh_A03G0087 & \multirow{5}{*}{$\begin{array}{l}\text { AT5G47500 } \\
\text { AT1G65570 } \\
\text { AT4G13710 }\end{array}$} & \multirow[t]{5}{*}{ Pectin lyase-like superfamily protein } & -3.5536 & $1.03 \mathrm{E}-10$ \\
\hline & PLL & Gh_A10G1707 & & & -4.0659 & 0.0010399 \\
\hline & PLL & Gh_D03G1564 & & & -2.7246 & $7.22 \mathrm{E}-10$ \\
\hline & PLL & Gh_D05G3049 & & & -1.5099 & 0.011417 \\
\hline & PLL & Gh_D12G2158 & & & -2.0499 & 0.00090874 \\
\hline & GRP & Gh_D10G1727 & AT3G06780 & Glycine-rich protein & 1.0437 & 0.036293 \\
\hline & HRGP & Gh_A06G1050 & AT3G25690 & \multirow{2}{*}{$\begin{array}{l}\text { Hydroxyproline-rich glycoprotein family } \\
\text { protein }\end{array}$} & -1.3346 & 0.027913 \\
\hline & HRGP & Gh_D11G0769 & AT3G02120 & & -1.742 & 0.00058494 \\
\hline \multirow{6}{*}{$\begin{array}{l}\text { 5. Differentiation and secondary } \\
\text { wall formation }\end{array}$} & GER3 & Gh_A05G3949 & AT5G20630 & Germin 3 & -1.8095 & 0.012068 \\
\hline & TPX1 & Gh_D05G1251 & AT1G65980 & Thioredoxin-dependent peroxidase 1 & 1.0563 & 0.029966 \\
\hline & PRX & Gh_A07G0275 & AT2G24800 & \multirow[t]{4}{*}{ Peroxidase superfamily protein } & -1.5209 & 0.00086829 \\
\hline & PRXR1 & Gh_A05G0507 & AT2G24800 & & -2.0256 & 0.037339 \\
\hline & PRX52 & Gh_A09G2334 & AT5G05340 & & 1.4635 & 0.0033052 \\
\hline & PRX53 & Gh_D08G2420 & AT5G06720 & & -3.5232 & 0.0049155 \\
\hline \multirow{9}{*}{$\begin{array}{l}\text { 6. Signaling and response } \\
\text { mechanisms }\end{array}$} & PR5 & Gh_A01G1376 & AT4G38670 & \multirow{3}{*}{$\begin{array}{l}\text { Pathogenesis-related thaumatin superfamily } \\
\text { protein }\end{array}$} & 1.3177 & 0.0017125 \\
\hline & PR5 & Gh_A03G0347 & AT2G28790 & & 1.6781 & 0.031724 \\
\hline & PR5 & Gh_D12G0310 & AT4G38670 & & 1.3177 & 0.0017125 \\
\hline & LTPG & Gh_A08G0720 & AT1G55260 & Lipid-transfer protein & 0.81073 & 0.046398 \\
\hline & LTPG & Gh_A08G1543 & Al2G45180 & & 1.9495 & 0.022371 \\
\hline & LTPG & Gh_D08G1844 & & & 1.2797 & 0.011976 \\
\hline & LTPG & Gh_A07G0235 & & & 0.88365 & 0.016833 \\
\hline & LYM2 & Gh_A12G0303 & AT2G17120 & Lysm domain GPI-anchored protein 2 & -1.5656 & 0.040813 \\
\hline & LYM2 & Gh_D12G0361 & & precursor & -1.4063 & 0.0022 \\
\hline \multirow[t]{8}{*}{ 7. Others } & SKS4 & Gh_A06G1309 & \multirow[t]{2}{*}{ AT4G22010 } & \multirow[t]{2}{*}{ SKU5 similar 4} & -1.3884 & 0.046854 \\
\hline & SKS4 & Gh_D06G1637 & & & -1.8953 & 0.0019284 \\
\hline & PMEI & Gh_A08G1555 & \multirow{4}{*}{$\begin{array}{l}\text { AT5G20740 } \\
\text { AT5G62360 }\end{array}$} & \multirow{4}{*}{$\begin{array}{l}\text { Plant invertase/pectin methylesterase } \\
\text { inhibitor superfamily protein }\end{array}$} & 1.3284 & 0.00058494 \\
\hline & PMEl & Gh_D03G1026 & & & -2.289 & $3.90 \mathrm{E}-13$ \\
\hline & PMEI & Gh_D05G0356 & & & 1.1199 & 0.0018667 \\
\hline & PMEI & Gh_D08G1863 & & & 1.2925 & 0.00051083 \\
\hline & ClF1 & Gh_D10G1801 & \multirow[t]{2}{*}{ AT1G47960 } & \multirow{2}{*}{$\begin{array}{l}\text { Cell wall / vacuolar inhibitor of fructosidase } \\
1\end{array}$} & 1.1969 & 0.00078794 \\
\hline & ClF1 & Gh_A10G1552 & & & 0.85616 & 0.047869 \\
\hline
\end{tabular}

HyPRP1 is potentially down-regulated by SA in cotton resistance against $V$. dahliae

Upon pathogen attack, plants can rapidly initiate an immune response that is regulated by specific phytohormones, which vary greatly in composition, quantity and timing $[23,24]$. Through analysis of differential gene expression and transcription profiling of cotton inoculated with $V$. dahliae, SA-, ABA-, JA- and ET-mediated signaling pathways have been proven to contribute to $V$. dahliae resistance $[14,25]$. ABRE (ABA-responsive element) 
Table 3 DEGs involving in regulating ROS blance

\begin{tabular}{|c|c|c|c|c|}
\hline Cotton ID & $\log 2 \mathrm{FC}$ & padj & Arabidopsis ID & Biological function \\
\hline Gh_D05G1251 & 1.0563 & 0.029966 & AT1G65980 & Thioredoxin-dependent peroxidase 1 \\
\hline Gh_D10G1930 & -2.4149 & $6.56 \mathrm{E}-07$ & AT3G06730 & Thioredoxin z \\
\hline Gh_A10G1673 & -2.3963 & 0.0013815 & AT3G06730 & Thioredoxin z \\
\hline Gh_A05G3692 & -1.1174 & 0.006171 & AT1G76760 & Thioredoxin Y1 \\
\hline Gh_D11G1225 & 1.4097 & $2.15 E-05$ & AT2G30540 & Thioredoxin superfamily protein \\
\hline Gh_D09G1113 & -1.432 & 8.29E-05 & AT2G31840 & Thioredoxin superfamily protein \\
\hline Gh_D08G2582 & 1.5176 & 0.0029746 & AT4G33040 & Thioredoxin superfamily protein \\
\hline Gh_D05G2291 & 0.96122 & 0.0058703 & AT4G03520 & Thioredoxin superfamily protein \\
\hline Gh_D05G0426 & 1.1171 & 0.012918 & AT4G33040 & Thioredoxin superfamily protein \\
\hline Gh_A12G0064 & 1.0842 & 0.03541 & AT2G30540 & Thioredoxin superfamily protein \\
\hline Gh_A11G1072 & 1.4971 & 8.01E-06 & AT2G30540 & Thioredoxin superfamily protein \\
\hline Gh_A09G1107 & -1.1404 & 0.0022929 & AT2G31840 & Thioredoxin superfamily protein \\
\hline Gh_A05G2047 & 1.0221 & 0.0026406 & AT4G03520 & Thioredoxin superfamily protein \\
\hline Gh_A05G0320 & 2.1073 & 0.0079978 & AT4G33040 & Thioredoxin superfamily protein \\
\hline Gh_A01G0925 & 0.93891 & 0.0080796 & AT3G51030 & Thioredoxin H-type 1 \\
\hline Gh_D12G1273 & -0.85546 & 0.036125 & AT2G47470 & Thioredoxin family protein \\
\hline Gh_D07G2378 & -2.2432 & 0.0089634 & AT4G29720 & Polyamine oxidase 5 \\
\hline Gh_A08G1751 & 1.1958 & 0.0029528 & AT5G21105 & Plant L-ascorbate oxidase \\
\hline Gh_A11G0771 & 0.86508 & 0.024855 & AT1G01820 & Peroxin 11c \\
\hline Gh_D07G0417 & 0.83262 & 0.032604 & AT3G47430 & Peroxin 11B \\
\hline Gh_A07G0355 & 1.0949 & 0.0017285 & AT3G47430 & Peroxin 11B \\
\hline Gh_A09G2334 & 1.4635 & 0.0033052 & AT5G05340 & Peroxidase superfamily protein \\
\hline Gh_A07G0275 & -1.5209 & 0.00086829 & AT2G24800 & Peroxidase superfamily protein \\
\hline Gh_A05G0507 & -2.0256 & 0.037339 & AT2G24800 & Peroxidase superfamily protein \\
\hline Gh_D08G2420 & -3.5232 & 0.0049155 & AT5G06720 & Peroxidase 2 \\
\hline Gh_D01G1856 & -1.675 & 0.01222 & AT1G77510 & PDI-like 1-2 \\
\hline Gh_A05G3724 & -1.0492 & 0.012948 & AT1G21750 & PDI-like 1-1 \\
\hline Gh_A04G0409 & 0.88963 & 0.01631 & AT1G17180 & Glutathione S-transferase TAU 25 \\
\hline Gh_A04G0830 & 0.77974 & 0.047869 & AT1G59700 & Glutathione S-transferase TAU 16 \\
\hline Gh_D13G0032 & -2.0914 & 0.045894 & AT5G01420 & Glutaredoxin family protein \\
\hline Gh_D12G0079 & 1.7875 & 0.010834 & AT2G47880 & Glutaredoxin family protein \\
\hline Gh_D11G0244 & 1.1813 & 0.00090549 & AT1G64500 & Glutaredoxin family protein \\
\hline Gh_A11G0230 & 1.2723 & 0.0011017 & AT1G64500 & Glutaredoxin family protein \\
\hline Gh_A09G1302 & -1.7113 & 0.047546 & AT5G03870 & Glutaredoxin family protein \\
\hline Gh_A05G2978 & -2.0779 & $7.21 \mathrm{E}-07$ & AT5G40760 & Glucose-6-phosphate dehydrogenase 6 \\
\hline Gh_D07G0457 & 1.2396 & 0.036439 & AT5G51100 & Fe superoxide dismutase 2 \\
\hline Gh_A07G0392 & -1.4372 & 0.0035132 & AT5G51100 & Fe superoxide dismutase 2 \\
\hline Gh_D11G1719 & -0.94414 & 0.01944 & AT1G65930 & Cytosolic NADP+- dependent isocitrate dehydrogenase \\
\hline Gh_A05G0722 & -2.2649 & 0.0088139 & AT2G28190 & Copper/zinc superoxide dismutase 2 \\
\hline Gh_D03G0021 & 1.3352 & 0.023812 & AT4G35090 & Catalase 2 \\
\hline Gh_A13G0827 & 1.1257 & 0.0022698 & AT1G08570 & Atypical CYS HIS rich thioredoxin 4 \\
\hline Gh_D10G2577 & 1.2429 & 0.034842 & AT5G65110 & Acyl-coa oxidase 2 \\
\hline
\end{tabular}



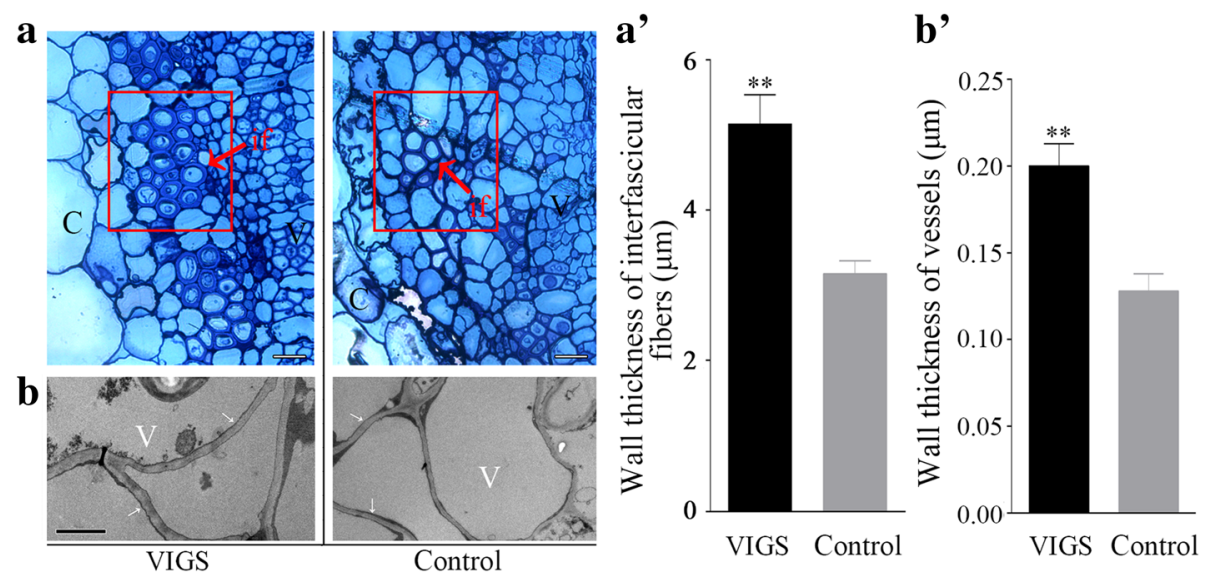

Fig. 6 Cell wall thickening in interfascicular fibers and vessels in HyPRP1-silenced cotton plants at 14 days post inoculation with $V$. dahliae. a Cross-sections of the vascular bundle region of the control and HyPRP1-silenced plants. Scale bar $=10 \mu \mathrm{m}$. C, cortex; if, interfascicular fiber; $v$, vessel. a', Measurement and statistical analysis of cell wall thickness in interfascicular fibers. $\mathbf{b}$, Transmission electron micrographs of vessel walls of the control and HyPRP1-silenced plants. Scale bar $=2 \mu \mathrm{m}$. b', Measurement and statistical analysis of cell wall thickness in vessels. 10-day-old seedlings with two fully expanded cotyledons were used for VIGS. After two weeks later HyPRP1-silenced plants were inoculated with V. dahliae. For each treatment, six separate plants were examined. 10 or more cells were measured for each plant. Data shown are means \pm SE of three independent experiments. Asterisks indicate a statistically significant difference according to the non-parametric Mann Whitney test (**P $<0.01$ )

(-292), TCA-element and ERE (ethylene responsive element) (-1128) have been reported in the upstream region of many genes that showed regulated expression in response to ABA, SA and ET, respectively [26-28]. In this paper, these potential cis-regulatory elements were also found in $p G b H y P R P 1$ (Fig. 5b). Furthermore, the expression profiles of GbHyPRP1 following treatment with these phytohormones were examined. The expression of GbHyPRP1 was significantly down-regulated by SA but up-regulated by ABA, JA and ET (Fig. 5c). Activation of complicated and concerted phytohormone signaling networks is an important regulatory mechanism of immunity employed by plants. In many cases, these hormones interact antagonistically or synergistically with each other [29]. Generally, pathogens that require a living host (biotrophs) are implicated in SA-mediated defense responses, whereas pathogens that kill the host and feed on the contents (necrotrophs) are associated with JA/ET-mediated defenses [23, 30]. Interestingly, however, $V$. dahliae is a hemibiotrophic phytopathogenic fungus. Thus, we infer that HyPRP1 taking part in cotton resistance to $V$. dahliae is probably regulated by a complex phytohormone signaling network. The HyPRP1 transcript levels showed quite similar down-regulation in SA-treated and $V$. dahliae-inoculated cotton seedlings (Figs. $1 \mathrm{~d}, 2 \mathrm{~b}$ and $5 \mathrm{c}$ ). Additionally, $V$. dahliae infection significantly increased SA levels in G. thurberi [31], G. hirsutum and G. barbadense seedlings (our unpublished data). Thus, we speculate that HyPRP1 may be mainly and negatively regulated by SA signaling in cotton resistance against V. dahliae.

\section{HyPRP1 participates in complex interactions within the cell wall polymer network in cotton infected with $V$. dahliae}

Cell wall proteins are essential constituents of plant cell walls and are involved in modification of the cell wall structure [32]. Arabinogalactan protein 31 (AGP31), a remarkable plant cell-wall protein, comprises an SP, a short AGP domain, an His-stretch, a PRD and a PAC (PRP-AGP containing Cys) domain [33-35]. Arabidopsis AGP31 is able to bind methylesterified polygalacturonic acid, possibly through its His-stretch, and to interact with itself in vitro through its PAC domain [34]. Similarly, cotton HyPRP1 also contains an SP, a basic histidine-rich domain embedded within the PRD and a cysteine-containing domain embedded within the Pollen Ole e I domain (Fig. 1a and Additional file 1: Figure S1). The cell wall, a physical barrier that pathogens need to breach to colonize the host plant, is typically reinforced with the phenolic polymer lignin $[36,37]$. Lignin is believed to play a critical role in the resistance of cotton to $V$. dahliae [13]. By comparative transcriptome analysis of HyPRP1-silenced cotton plants and the control inoculated with $V$. dahliae, 79 DEGs potentially involved in cell wall biogenesis were identified (Table 2). Of these genes, Gh_D13G1445 was described as a Mannose-1-phosphate guanylyltransferase catalyzing the production of GDP-mannose. Arabidopsis cyt1 (encodes mannose-1-phosphate guanylyltransferase) mutant cause changes in the cell wall composition, such as dramatic decrease in cellulose content [38]. UDP-glycosyltransferases (UGTs) can influence the resistance of plants to infection by pathogenic microorganisms through regulating the 

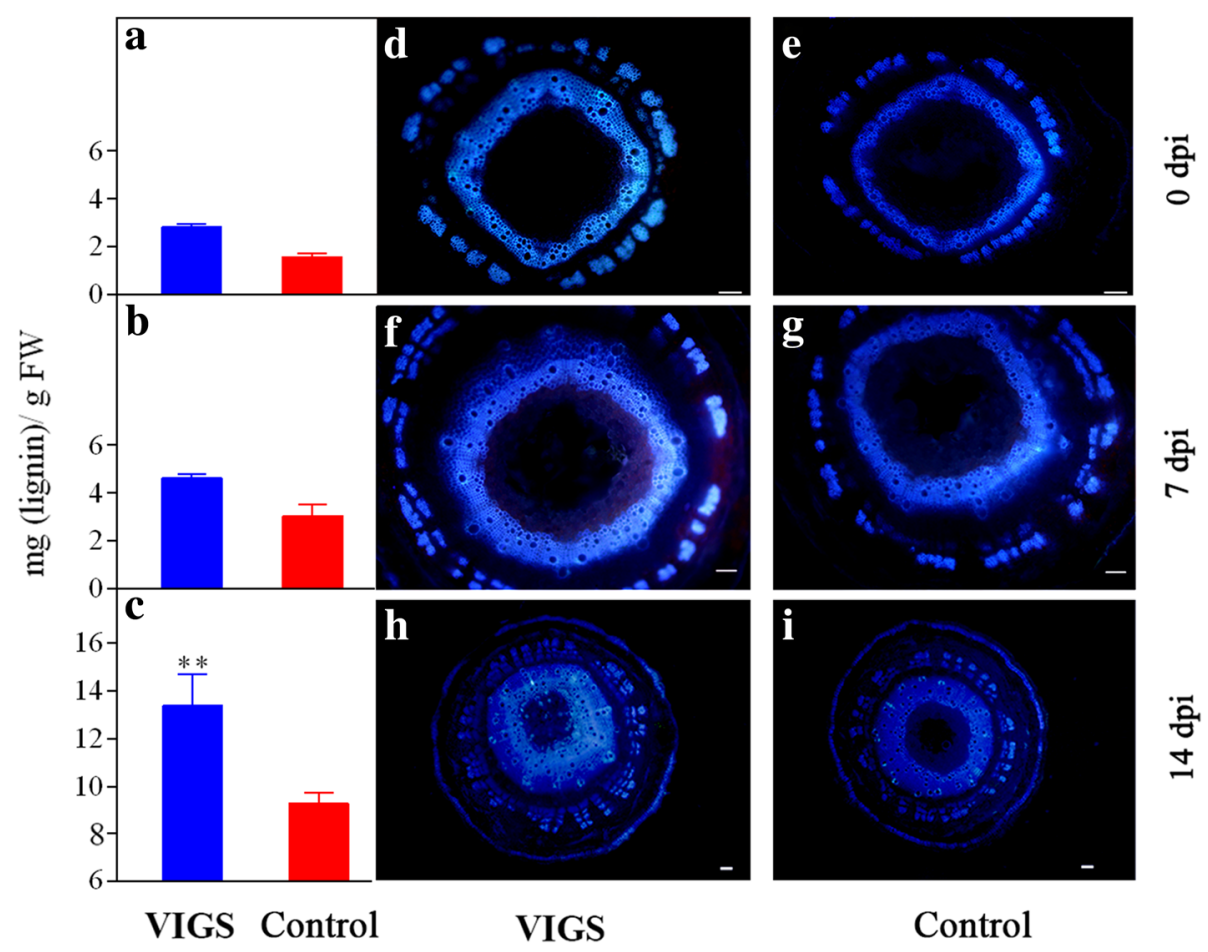

Fig. 7 Analysis of lignin in stems of HyPRP1-silenced cotton plants after inoculation with $V$. dahliae. 10-day-old seedlings with two fully expanded cotyledons were used for VIGS. After two weeks later HyPRP1-silenced plants were inoculated with V. dahliae. Measurement and statistical analysis of the lignin content in cotton stems after inoculation with $V$. dahliae at $0 \mathrm{dpi}(\mathbf{a}), 7 \mathrm{dpi}(\mathbf{b})$ and $14 \mathrm{dpi}(\mathbf{c})$. At each time point of each treatment, three separate plants were examined. The results show means \pm SE of values for three independent experiments. Asterisks indicate a statistically significant difference according to Sidak's multiple comparisons test (**P $<0.01$ ). Fluorescence microscopy of a $1-\mathrm{cm}$ transverse stem section from control and HyPRP1-silenced cotton plants at 0 dpi (d\&e), $7 \mathrm{dpi}(\mathbf{f} \& \mathbf{g})$ and $14 \mathrm{dpi}(\mathbf{h} \& \mathbf{i})$. Bar $=50 \mu \mathrm{m}$. Lignin autofluorescence was visualized following ultraviolet excitation at $365 \mathrm{~nm}$

glycosylation of phenylpropanoid and phenylpropanoid-de rived compounds, which are essential for the synthesis of lignin [39]. The xyloglucan endotransglucosylase/hydrolases (XTHs), specifically hydrolyzing xyloglucan as a substrate, are considered to be involved in the construction and restructuring of xyloglucan cross-link in plant cell wall [40]. Calmodulin, a highly conserved $\mathrm{Ca}^{2+}$-binding protein, acts as an intermediary connecting $\mathrm{Ca}^{2+}$ signals involved in plant defence reactions [41]. Most of DEGs mentioned above have higher transcript levels in $H y P R P 1$-silenced plants, suggesting that $H y P R P 1$ is a negative regulator of cell wall-related genes. Further, we observed a dramatic thickening of interfascicular fiber walls and vessel walls (Fig. 6) and an increase in lignin (Fig. 7) in the HyPRP1-silenced cotton plants compared with the control after inoculation with $V$. dahliae. On the other hand, some DEGs were down-regulated, which seems to be a negative impact on cell-wall thickening and lignin accumulation. For example, phenylalanine ammonia-lyase (PAL) is the first committed enzyme in the phenylpropanoid biosynthesis, which engenders a variety of precursors of important secondary metabolites, mainly including flavonol glycosides and lignin. In our study,
PAL2 (Gh_D06G0758) was shown to be significantly downregulated. We inferred that $P A L$ transcription was feedback regulated by particular biosynthetic intermediates [42], which means that the expression of $P A L$ may not be always positive correlation with lignin accumulation. Although the roles of many cell wall proteins have been studied broadly, the knowledge on the interaction between components is lacking. Thus, we speculated that HyPRP1 participates in complex interactions within the cell wall polymer network in cotton infected with $V$. dahliae.

\section{HyPRP1 contributes to Veticillum defense by enhancing ROS accumulation}

ROS have been studied extensively for their roles in interactions between plants and foliar pathogens. Little is known about ROS synthesis and function in defense reactions of the root, but ROS are consistently observed to accumulate in a plant after the perception of pathogens [18]. In the Verticillium-cotton interaction, the generation of $\mathrm{H}_{2} \mathrm{O}_{2}$ was observed in the roots of cotton infected with $V$. dahliae [43]. Moreover, transgenic tomato plants expressing the $V e$ resistance gene accumulated 
a

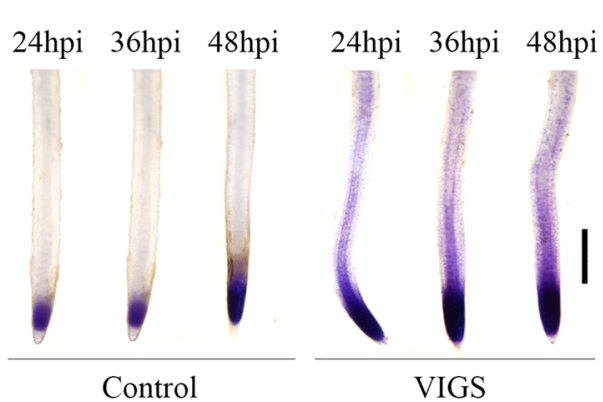

b

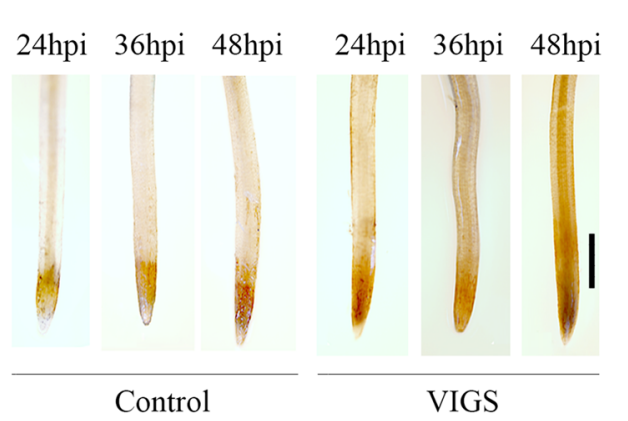

C
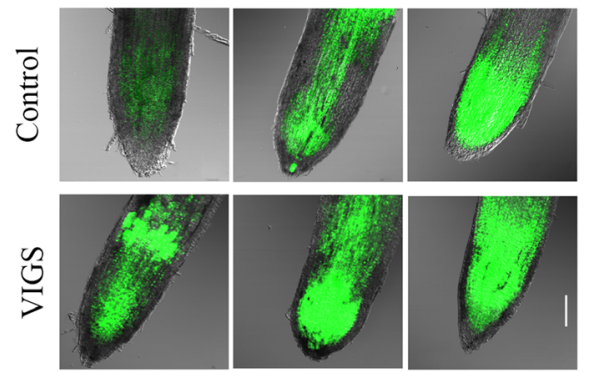

24hpi

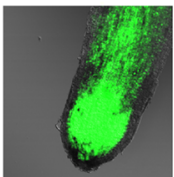

36hpi

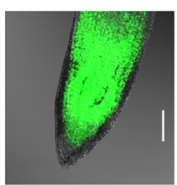

48hpi
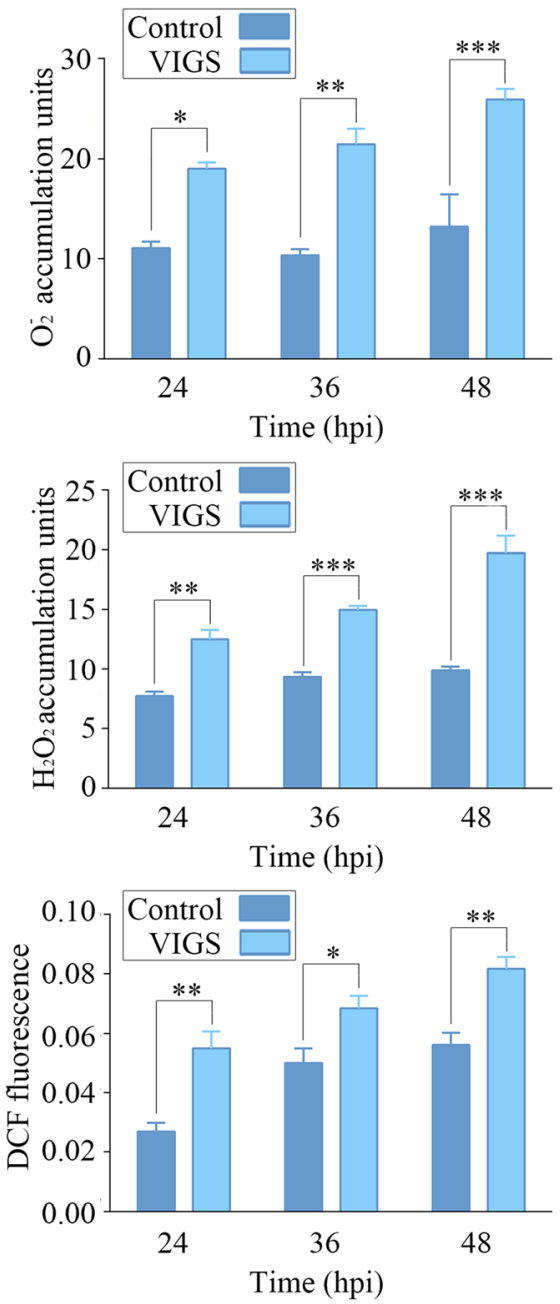

Fig. 8 Comparison of ROS accumulation in root tips of HyPRP1-silenced cotton seedlings inoculated with V. dahliae. a Representative microphotographs of NBT staining. The roots were inoculated with NBT for 40 min and were then subjected to microscopic observation to determine $\mathrm{O}_{2}{ }^{-}$production. Scale bar $=1 \mathrm{~mm}$. b Representative microphotographs of DAB staining. The roots were placed in DAB for $10 \mathrm{~h}$ and were then subjected to microscopic observation to determine $\mathrm{H}_{2} \mathrm{O}_{2}$ production. Scale bar $=1 \mathrm{~mm}$. c Representative confocal images of DCFH-DA staining. The roots were placed in DCFH-DA for $30 \mathrm{~min}$ and were then examined to determine ROS production. Scale bar $=100 \mu \mathrm{m}$. At each time point of each treatment, nine roots from three separate plants were examined. Data represent the means \pm SE from three biological replicates; asterisks indicate statistically significant differences according to Tukey's multiple comparisons test $\left(^{*} P<0.05\right.$, $\left.{ }^{* *} P<0.01,{ }^{* * *} P<0.001\right)$. 10-day-old seedlings with two fully expanded cotyledons were used for VIGS. After two weeks later HyPRP1-silenced plants were inoculated with $V$. dahliae

$\mathrm{H}_{2} \mathrm{O}_{2}$ upon $V$. dahliae infection [44]. Likewise, transgenic cotton plants expressing a fungal endochitinase gene were more resistant and accumulated ROS faster than the control following pathogen inoculation [45]. These results indicate that cotton plants infected with $V$. dahliae are accompanied by increased ROS accumulation. In our study, silencing of HyPRP1 markedly enhanced ROS accumulation in the root tips (Fig. 8). Therefore, we reasonably inferred that cotton negatively modulates HyPRP1 transcription to generate ROS used for defense against Veticillum. Further studies are needed to elucidate the roles of ROS in cotton resistance to Verticillium. However, we suggest that ROS perform three possible functions: (i) ROS are primary immune signaling molecules [46]; (ii) ROS mediate cell wall modifications [47]; and (iii) ROS are important modulators that play a role in defense-related protein post-trans lational modifications [48].

\section{Conclusions}

Based on our research and existing developments on how plants resist Verticillium wilt, we propose a model of HyPRP1-mediated cotton defense against $V$. dahliae. Upon $V$. dahliae attack, recognition by cotton plants results in the activation of immune responses, including the production of a specific combination of the signals 
such as SA and JA, which have been proved to be involved in the plant- $V$. dahliae interaction $[14,25]$. The expression of $H y P R P 1$ is most likely and mainly down -regulated by SA signaling. A significant reduction in HyPRP1 may affect the cell wall polymer network, including an increase in the thickness of the cell wall and the content of lignin required to prevent $V$. dahliae infection. Alternatively, down-regulation of HyPRP1 obviously enhances the accumulation of ROS, which could mediate the establishment of a cotton defensive response to $V$. dahliae.

\section{Methods}

\section{Plant materials and growth conditions}

The cotton seeds G. barbadense cv. Pima90-53, G. hirsutum cv. CCRI8 and ND601 were preserved at the North China Key Laboratory for Crop Germplasm Resources of Education Ministry, Hebei Agricultural University, Baoding, China. For transcriptional analysis of HyPRP1 in different tissues and response to $V$. dahliae by qPCR, two-week-old cotton seedlings were cultivated on Murashige and Skoog (MS) medium and were inoculated with $V$. dahliae as described by Zhang et al. [14]. For VIGS and the hormone treatment experiment, seeds were sterilized in $20 \%(\mathrm{~V} / \mathrm{V})$ commercial bleach (the final concentration of sodium hypochlorite was approximately $1 \%$ ) for $20 \mathrm{~min}$ followed by washing four times with distilled water. Seeds were soaked in distilled water for 2 days and then germinated on wet towels for another 2 days at $25^{\circ} \mathrm{C}$. Germinant seeds were transferred to pots containing commercially sterilized soil (a mixture of soil, peat, and composted pine bark) and covered with a plastic dome in a growth room at $25^{\circ} \mathrm{C}$ under a $14-\mathrm{h}$ light/10-h dark cycle. The A. thaliana accession Columbia was grown in commercially sterilized soil at $22{ }^{\circ} \mathrm{C}, 70 \%$ relative humidity, and $\sim 150 \mu \mathrm{E} \mathrm{m} \mathrm{m}^{-2} \mathrm{~s}^{-1}$ under a 9-h photoperiod.

\section{V. dahliae cultivation}

A highly aggressive defoliating fungus, $V$. dahliae strain Linxi2-1, was isolated from a symptomatic upland cotton plants growing in agricultural fields near Linxi, Hebei Province, China, and preserved in North China Key Laboratory for Crop Germplasm Resources of Education Ministry, Hebei Agricultural University. $V$. dahliae was cultivated on potato dextrose agar (PDA) plates for $10 \mathrm{~d}$ and then inoculated into Czapek's broth on a shaker at $150 \mathrm{rpm}$ for 1 week at $25^{\circ} \mathrm{C}$ in the dark. Spores were harvested by filtration through folded Fisherbrand ${ }^{\mathrm{Tx}}$ lens paper and were resuspended in sterile distilled water to a specific density.
Cloning of HyPRP1 and the GbHyPRP1 promoter region GbHyPRP1 was identified from a full-length cDNA library of G. barbadense Pima90-53 [14]. The full-length cDNA of HyPRP1 from other upland cotton cultivars was obtained by homology-based cloning. The genomic walking method was performed to amplify its 5' flanking (promoter) region using the Genome Walking Kit (Takara, Dalian, China) according to the manufacturer's instructions. Nested sequence-specific primers designed on the basis of the known GbHyPRP1 gene sequence and shorter arbitrary degenerate primers were chemically synthesized or provided by the kit. The HyPRP1 protein sequences were identified using NCBI Web BLAST (http://www.ncbi.nlm.nih.gov/) and were a ligned using the Clustal W program (http://www.clustal.org/). The promoter sequence was analyzed using the software programs PlantCARE and PLACE to define putative cis-elements or binding sites for transcription factors $[49,50]$.

\section{qPCR and semi-RT-qPCR analysis}

Total RNA was extracted using TRIzol $^{\circ}$ reagent (Invitrogen, Carlsbad, CA, USA) according to the manufacturer's instructions. Each treatment, imposed on three pooled root, stem or leaf samples, was repeated at least three times in all experiments. RNA was quantified using a NanoDrop $^{\text {Tw }} 1000$ Spectrophotomete (Thermo Fisher Scientific). Subsequently, first-strand cDNA was synthesized from $1 \mu \mathrm{g}$ of total RNA using the PrimeScript ${ }^{\mathrm{Tm}}$ RT Reagent Kit with gDNA Eraser (TaKaRa, Dalian, China). qPCR was performed using a CFX96 Real-Time PCR Detection System (Bio-Rad, Hercules, CA, USA) and SYBR ${ }^{\circ}$ Green reagent (TaKaRa, Dalian, China) as the reporter dye. Data were collected using CFX Manager ${ }^{\text {Tx }}$ software (Bio-Rad, Hercules, CA, USA). Target gene relative expression was normalized using PP2A1 (catalytic subunit of protein phosphatase 2A) [51]. For semi-RT-qPCR, the reactions were run with a denaturation step of $95^{\circ} \mathrm{C}$ for 5 min, followed by 25 cycles of $94{ }^{\circ} \mathrm{C}$ for $1 \mathrm{~min}, 55^{\circ} \mathrm{C}$ for 30 s, $72{ }^{\circ} \mathrm{C}$ for $1 \mathrm{~min}$, with a final extension at $72^{\circ} \mathrm{C}$ for 10 min. PCR products were electrophoresed on $1 \%$ agarose gels.

\section{Subcellular localization analysis of transiently expressed fusion proteins}

For subcellular localization studies, the GbHyPRP1 ORF was amplified using PCR. The resulting product was inserted into the vector pDONR ${ }^{\mathrm{rw}} 207$. Subsequently, the fragment was recombined into the destination vector pK7WGF2 [52] using L/R-Clonase. The construct was verified by sequencing and was transferred to the Agrobacterium tumefaciens GV3101 strain using the freeze/ thaw method [53]. Transient transformation of tobacco leaf epidermal cells was performed as described in [54]. 
Localization of fluorescent proteins was monitored 3 days after infiltration using a confocal laser scanning microscope (FluoView FV1000; Olympus). A pCAMBIA derivative (pCamE) carrying a cauliflower mosaic virus 35S-driven GFP was used as the control [55].

\section{Hormone treatments}

Cotton seedlings at the 2-cotyledon stage were sprayed with $100 \mu \mathrm{M}$ SA, ABA, JA or ET and were covered with plastic bags to maintain $100 \%$ humidity. Cotyledon tissues were collected from hormone-treated plants at 6 , $12,24,36$ and $48 \mathrm{hps}$, immediately frozen in liquid nitrogen and then stored at $-80^{\circ} \mathrm{C}$ until RNA extraction. The control seedlings were sprayed with distilled water.

\section{Generation of transgenic Arabidopsis lines}

The coding sequence of GbHyPRP1 was amplified from G. barbadense Pima90-53 cDNA and cloned into a pBI121 vector. A genomic GbHyPRP1 upstream fragment was amplified and cloned into the pBI121 vector containing beta-glucuronidase (GUS) gene coding sequences, where the $35 \mathrm{~S}$ promoter region was excised by digestion using PstI and BamHI restriction enzymes and was replaced with the sequence of the GbHyPRP1 upstream fragment. The recombinant plasmid was transformed into $A$. thaliana Columbia wild type (WT) plants through Agrobacterium tumefaciens strain G V3101-mediated plant transformation using the floral dip method [56]. Primary transformants were selected for survival on $1 / 2 \mathrm{MS}$ medium with $50 \mu \mathrm{g} \mathrm{ml}^{-1}$ kanamycin. Homozygous plants were isolated using gene-specific primers. Semi-RT-qPCR was then performed on cDNA from overexpression lines to confirm the status of transcription using the full-length $G b H y P R P 1$ primers. Expression was normalized to the expression of actin. T3 transgenic $A$. thaliana plants carrying the GbHyPRP1 promoter were used in histochemical assays for GUS staining as described by [57].

\section{VIGS assays in cotton}

pTRV1 and pTRV2 from the Yule Liu research group at Tsinghua University (China) were used for the VIGS assays [58]. HyPRP1 fragments (364 bp) were amplified (Additional file 5: Table S1) and inserted into the pTRV2 vector to generate the derivative pTRV-HyPRP1, which were transformed into A. tumefaciens strain GV3101. An Agrobacterium-mediated VIGS assay in cotton was performed as previously described [59]. Cotton seedings with two fully expanded cotyledons were utilized. At this stage, the true leaves had not yet emerged. The cloroplastos alterados 1 gene (CLA1) was used as a marker to monitor the silencing efficiency. The seedlings injected with Agrobacterium cultures harboring the pTRV1 and pTRV2 (empty vector) were used as control. VIGS assays were repeated at least three times using more than 30 plants from each treatment per repeat.

Twenty-four-day-old cotton seedlings were subjected to $V$. dahliae inoculation by root dipping in a spore suspension $\left(10^{7}\right.$ spores $\left.\mathrm{ml}^{-1}\right)$ for $2 \mathrm{~min}$ and were then returned to their original pots. Four-week-old Arabidopsis plants were infected with $V$. dahliae by soil drenching using a $10-\mathrm{ml}$ conidial suspension $\left(10^{6}\right.$ spores $\left.\mathrm{ml}^{-1}\right)$ per pot $(80 \mathrm{ml})$. Control plants were inoculated with distilled water in the same way. Cotton and Arabidopsis symptoms and disease index (DI) were scored at $15 \mathrm{dpi}$. The DI was calculated based on five disease grades as described previously [60]. Thirty-five plants were used per treatment, and each treatment was repeated three times. Plant resistance to $V$. dahliae was determined based on the DI, where $>35=$ susceptible, 20 to $35=$ tolerant, and 10 to $20=$ resistant (National Standards of the People's Republic of China GBT 22101.5-2009, Technical Specification for Evaluating Resistance of Cotton to Disease and Insect Pests - Part 5: Verticillium wilt).

\section{Primers}

All primers used in this paper are listed in Additional file 5: Table S1.

\section{RNA-Seq library construction and analysis of transcriptome sequencing data}

Two independent sets from both control and HyPRP1silenced plants were sampled to generate two biological replicas. For each sample, the first true leaves from at least six plants were collected at $12 \mathrm{hpi}$ and pooled to minimize plant-to-plant variation. Then, total RNA was extracted using $\mathrm{TRIzol}^{\circ}$ reagent following the manufacturer's instructions, after which genomic DNA was removed using DNase I (Invitrogen, Carlsbad, CA, USA). RNA purity was checked using a NanoPhotometer ${ }^{\circ}$ spectrophotometer (IMPLEN, CA, USA), and concentration was measured in a Qubit $^{\oplus} 2.0$ Flurometer using the Qubit $^{\circ}$ RNA Assay Kit (Life Technologies, CA, USA). RNA integrity was assessed using the RNA Nano 6000 Assay Kit of the Bioanalyzer 2100 system (Agilent Technologies, CA, USA). Transcriptome sequencing was performed using an Illumina HiSeqTM 2000 sequencer (Illumina, San Diego, CA, USA).

Sequence tag preprocessing was performed according to a previously described protocol [61]. Paired-end clean reads were aligned to the reference genome of G. hirsutum L. acc. TM-1 (https://www.cottongen.org/) using Bowtie v2.0.6 and TopHat v2.0.9. Differential expression analysis of HyPRP1-silenced and unsilenced (mock) groups (two biological replicates per group) was performed using the DESeq $\mathrm{R}$ package (1.10.1). The 
resulting $P$-values were adjusted using Benjamini and Hochberg's approach for controlling the false discovery rate. Genes with an adjusted $P<0.05$ according to DESeq were assigned as differentially expressed.

\section{Examination of cell walls}

Stems were cut into pieces $\left(1 \mathrm{~mm}^{3}\right)$ and fixed in $2.5 \%$ (wt/vol) glutaraldehyde in $0.1 \mathrm{M}$ phosphate buffer, postfixed in $1 \%$ osmium tetroxide, and then embedded in Spurr's resin. Semi-thin sections $(1 \mu \mathrm{m})$, prepared using a Leica UC6 (Leica, Illinois, USA), were hot-stained with a $1 \%$ toluidine blue water solution. Images were captured using a digital camera (Digital sight DS-L1, Nikon, Japan) attached to a Olympus BX51 microscope (Tokyo, Japan). Ultra-thin sections (70 $\mathrm{nm}$ thick), prepared using a Leica Ultracut R ultramicrotome (Leica, Illinois, USA), were stained with uranyl acetate and lead citrate and examined under a JEM-1230 electron microscope (JEOL Ltd., Tokyo, Japan). Approximately 60 cells were measured per sample to determine the thickness of the cell walls.

\section{Lignin extraction and quantification}

Stem samples were collected from both HyPRP1-silen ced and control plants at 0, 7 and $14 \mathrm{dpi}$. Three samples were collected per plant at different time intervals; the samples were crushed immediately in liquid nitrogen and freeze-dried. The extraction and quantification of lignin in cell walls were performed according to the method of Schenk et al., 2014 [62].

\section{Identifiction of lignin deposition in cell walls using histochemistry and autofluorescence}

Standard transverse free-hand sections were collected from the stems of cotton seedlings $(5 \mathrm{~cm}$ from the stem base). Lignin autofluorescence was imaged using a BX51 microscope with both UV excitation and brightfield modes.

\section{Biological analysis of ROS accumulation}

Since ROS include various forms of reduced and chemically reactive molecules such as hydrogen peroxide $\left(\mathrm{H}_{2} \mathrm{O}_{2}\right)$ and the superoxide oxygen anion $\left(\mathrm{O}_{2}{ }^{-}\right)$, we used NBT and DAB dyes, as well as the ROS-reactive fluorescent probe DCFH-DA, to detect the accumulation of ROS. Yellow, water-soluble NBT can be reduced by $\mathrm{O}_{2}{ }^{-}$ to blue, water-insoluble formazan. DAB polymerizes at sites of peroxidase activity into a reddish brown polymer in the presence of $\mathrm{H}_{2} \mathrm{O}_{2}$. Fluorescence-free DCFH-DA can cross the cell membrane and, after hydrolyzation, be oxidized by ROS to form highly fluorescent DCF [18]. $\operatorname{ROS}\left(\mathrm{H}_{2} \mathrm{O}_{2}\right)$ accumulation was visualized by incubating intact cotton roots in $5 \mu \mathrm{M}$ DCFH-DA (dichlorofluorescein diacetate; Beyotime, Nanjing, China) for $20 \mathrm{~min}$ at $37^{\circ} \mathrm{C}$ in the dark or in $10 \mathrm{mM} \mathrm{K-citrate} \mathrm{buffer} \mathrm{(pH} \mathrm{6.0)}$ containing $2.5 \mathrm{mM}$ DAB (3,3'-diaminobenzidine) for 12 $\mathrm{h}$, as described by [63]. $\mathrm{ROS}\left(\mathrm{O}_{2}{ }^{-}\right)$production was also visualized by incubating intact roots in $10 \mathrm{mM} \mathrm{K}$-citrate buffer (pH 6.0) containing $0.5 \mathrm{mM} \mathrm{NBT}$ (nitrotetrazolium blue chloride) for $30 \mathrm{~min}$ at $37^{\circ} \mathrm{C}$. An Olympus FV1000 laser confocal microscope with an excitation wavelength of $488 \mathrm{~nm}$ was used for the analysis of DCF fluorescence. For DAB and NBT staining, the roots were boiled in $95 \%$ ethanol for $10 \mathrm{~min}$ and then rinsed twice with $50 \%$ ethanol, after which images were captured under a light microscope (BX51; Olympus, Tokyo, Japan) using a digital camera (DP71; Olympus, Tokyo, Japan) and Image-Pro ${ }^{\circ}$ Plus 6.0 software (Media Cybernetics, Rockville, MD, USA). Quantization of fluorescence and coloration intensity was performed using ImageJ software version 1.48 (National Institute of Mental Health, Bethesda, MD, USA).

\section{Statistical analysis}

All experiments were repeated at least three times for each determination. Statistical analysis of data was conducted with the software of GraphPad Prism ${ }^{\circ} 6$ (Graph Pad, San Diego, CA, USA). The P-value less than 0.05 was considered to be statistically significant.

\section{Additional files}

\begin{abstract}
Additional file 1: Figure S1. Alignment of the amino acid sequences of Sea Island cotton Pima90-53 HyPRP1 with those of six other upland cotton cultivars including TM-1, Coker312, ND601, CCRI8, JiMian20, and NongDaMian7. The alignment results showed that HyPRP1 shares a significant degree of sequence identity in cotton. (TIF $615 \mathrm{~kb}$ )
\end{abstract}

Additional file 2: Figure S2. A DNA fragment upstream of the GbHyPRP1 coding sequence was isolated and then designated as PGbHyPRP1, which is $1431 \mathrm{bp}$ in length and contains 41 nucleotides of the $5^{\prime}$-terminal regions of the GbHyPRP1 cDNA. The first base of the CDNA was designated as the putative transcription start site $(+1)$. (TIF $2613 \mathrm{~kb}$ )

Additional file 3: Figure S3. At approximately two weeks post Agrobacterium infiltration, the leaves of CLA1-VIGS plants started to displayed the albino phenotype on the true leaves (A). At the same time, the silencing of HyPRP1 gene expression in VIGS and control plants was confirmed by semi-RT-qPCR analysis (B). (TIF $9955 \mathrm{~kb}$ )

Additional file 4: Data S1. DEGs in V12 (VIGS at $12 \mathrm{hpi}$ ) versus $\mathrm{C} 12$ (Control at 12 hpi) using Padj (adjusted P) value < 0.05 as criteria. (XLSX 106 kb) Additional file 5: Table S1. Primers used in this study. (DOCX 15 kb)

Abbreviations

ABA: Abscisic acid; CLA1: Cloroplastos alterados 1; DEGs: Differentially expressed genes; DI: Disease index; ET: Ethylene; GUS: beta-glucuronidase; HyPRP: Hybrid proline-rich protein; JA: Jasmonic acid; ORF: Open reading frame; PDA: Potato dextrose agar; ROS: Reactive oxygen species; SA: Salicylic acid; VIGS: Virus-induced gene silencing; WT: Wild type

\section{Acknowledgments}

All authors are grateful to the laboratory members for help, advice and discussion. 


\section{Funding}

This research was financially supported by the National Natural Science Foundation of China (No. 31301370), the Fund of the China Agriculture Research System (CARS18-08) and Science and Technology Support Program of Hebei Province (16226307D).

\section{Availability of data and materials}

All sequence reads analyzed during the current study have been deposited in the NCBI Genbank datasets (https://www.ncbi.nlm.nih.gov/genbank) under the SRA accession PRJNA490422. Other data generated or analyzed during the current study are included in this published article and its supplementa data files and available from the corresponding author on reasonable request.

\section{Authors' contributions}

YJ and MZY designed the experiments. YJ carried out the study and wrote the manuscript. ZY, WXF, WWQ and WGN performed the experiments. LZK, WJH, WLQ and ZGY carried out the data analysis. All authors discussed the results and reviewed the manuscript. All authors read and approved the final manuscript.

\section{Ethics approval and consent to participate}

Not applicable.

\section{Consent for publication}

Not applicable.

\section{Competing interests}

The authors declare that they have no competing interests.

\section{Publisher's note}

Springer Nature remains neutral with regard to jurisdictional claims in published maps and institutional affiliations.

Received: 8 May 2018 Accepted: 22 November 2018 Published online: 07 December 2018

\section{References}

1. Cassab Gl. Plant cell wall proteins. Annu Rev Plant Physiol Plant Mol Biol. 1998;49(1):281-309.

2. Josè-Estanyol M, Puigdomènech P. Plant cell wall glycoproteins and their genes. Plant Physiol Biochem. 2000;38(1-2):97-108.

3. Yeom SI, Seo E, Oh SK, Kim KW, Choi D. A common plant cell-wall protein HyPRP1 has dual roles as a positive regulator of cell death and a negative regulator of basal defense against pathogens. Plant J. 2012;69(5):755-68.

4. Neto LB, de Oliveira RR, Wiebke-Strohm B, Bencke M, Weber RL, Cabreira C, Abdelnoor RV, Marcelino FC, Zanettini MH, Passaglia LM. Identification of the soybean HyPRP family and specific gene response to Asian soybean rust disease. Genet Mol Biol. 2013;36(2):214-24.

5. Xu D, Huang $X, X u Z Q$, Schlappi M. The HyPRP gene EARLI1 has an auxiliary role for germinability and early seedling development under low temperature and salt stress conditions in Arabidopsis thaliana. Planta. 2011;234(3):565-77.

6. Huang G, Gong S, Xu W, Li P, Zhang D, Qin L, Li W, Li X. GhHyPRP4, a cotton gene encoding putative hybrid proline-rich protein, is preferentially expressed in leaves and involved in plant response to cold stress. Acta Biochim Biophys Sin Shanghai. 2011:43(7):519-27.

7. Priyanka B, Sekhar K, Reddy VD, Rao KV. Expression of pigeonpea hybridproline-rich protein encoding gene (CCHyPRP) in yeast and Arabidopsis affords multiple abiotic stress tolerance. Plant Biotechnol J. 2010;8(1):76-87.

8. Sheng J, D'Ovidio R, Mehdy MC. Negative and positive regulation of a novel proline-rich protein mRNA by fungal elicitor and wounding. Plant J. 1991; 1(3):345-54

9. Zhang S, Mehdy MC. Binding of a $50-k D$ protein to a U-rich sequence in an mRNA encoding a proline-rich protein that is destabilized by fungal elicitor. Plant Cell. 1994;6(1):135-45.

10. Yingfan C, Xiaohong $\mathrm{H}, \mathrm{Mo}$ J, Sun $\mathrm{Q}$, Yang J, Liu J. Molecular research and genetic engineering of resistance to Verticillium wilt in cotton: a review. Afr J Biotechnol. 2009;8(25):7363-72.

11. Rommens CM, Kishore GM. Exploiting the full potential of disease-resistance genes for agricultural use. Curr Opin Biotechnol. 2000;11(2):120-5.
12. Gao W, Long L, Zhu LF, Xu L, Gao WH, Sun LQ, Liu LL, Zhang XL. Proteomic and virus-induced gene silencing (VIGS) analyses reveal that gossypol, brassinosteroids, and jasmonic acid contribute to the resistance of cotton to Verticillium dahliae. Mol Cell Proteomics. 2013;12(12):3690-703.

13. Xu L, Zhu L, Tu L, Liu L, Yuan D, Jin L, Long L, Zhang X. Lignin metabolism has a central role in the resistance of cotton to the wilt fungus Verticillium dahliae as revealed by RNA-Seq-dependent transcriptional analysis and histochemistry. J Exp Bot. 2011;62(15):5607-21.

14. Zhang Y, Wang XF, Ding ZG, Ma Q, Zhang GR, Zhang SL, Li ZK, Wu LQ, Zhang GY, Ma ZY. Transcriptome profiling of Gossypium barbadense inoculated with Verticillium dahliae provides a resource for cotton improvement. BMC Genomics. 2013;14:637.

15. Mo H, Wang X, Zhang Y, Zhang G, Zhang J, Ma Z. Cotton polyamine oxidase is required for spermine and camalexin signalling in the defence response to Verticillium dahliae. Plant J. 2015;83(6):962-75.

16. Zhang TZ, Hu Y, Jiang WK, Fang L, Guan XY, Chen JD, Zhang JB, Saski CA, Scheffler BE, Stelly DM, et al. Sequencing of allotetraploid cotton (Gossypium hirsutum L. acc. TM-1) provides a resource for fiber improvement. Nat Biotechnol. 2015:33(5):531-7.

17. Tenhaken R. Cell wall remodeling under abiotic stress. Front Plant Sci. 2015; 5(771):771.

18. Lehmann S, Serrano M, L'Haridon F, Tjamos SE, Metraux J-P. Reactive oxygen species and plant resistance to fungal pathogens. Phytochemistry. 2014;112:54-62.

19. Deutch CE, Winicov I. Post-transcriptional regulation of a salt-inducible alfalfa gene encoding a putative chimeric proline-rich cell wall protein. Plant Mol Biol. 1995;27(2):411-8.

20. Castonguay $Y$, Laberge $S$, Nadeau P, Vezina LP. A cold-induced gene from Medicago sativa encodes a bimodular protein similar to developmentally regulated proteins. Plant Mol Biol. 1994;24(5):799-804.

21. Goodwin W, Pallas JA, Jenkins Gl. Transcripts of a gene encoding a putative cell wall-plasma membrane linker protein are specifically cold-induced in Brassica napus. Plant Mol Biol. 1996;31(4):771-81.

22. He CY, Zhang JS, Chen SY. A soybean gene encoding a proline-rich protein is regulated by salicylic acid, an endogenous circadian rhythm and by various stresses. Theor Appl Genet. 2002;104(6-7):1125-31.

23. Koornneef A, Pieterse CM. Cross talk in defense signaling. Plant Physiol. 2008;146(3):839-44.

24. Singh KB, Foley RC, Oñate-Sánchez L. Transcription factors in plant defense and stress responses. Curr Opin Plant Biol. 2002;5(5):430-6.

25. Xu L, Zhu LF, Tu LL, Guo XP, Long L, Sun LQ, Gao W, Zhang XL. Differential gene expression in cotton defence response to Verticillium dahliae by $\mathrm{SSH}$. J Phytopathol. 2011;159(9):606-15.

26. Bonetta $D$, McCourt P. Genetic analysis of ABA signal transduction pathways. Trends in Plant Sci. 1998:3(6):231-5.

27. Goldsbrough AP, Albrecht H, Stratford R. Salicylic acid-inducible binding of a tobacco nuclear protein to a 10 bp sequence which is highly conserved amongst stress-inducible genes. Plant J. 1993;3(4):563-71.

28. Vahala J, Felten J, Love J, Gorzsás A, Gerber L, Lamminmäki A, Kangasjärvi J, Sundberg B. A genome-wide screen for ethylene-induced ethylene response factors (ERFs) in hybrid aspen stem identifies ERF genes that modify stem growth and wood properties. New Phytol. 2013;200(2):511-22.

29. Kazan K, Lyons R. Intervention of phytohormone pathways by pathogen effectors. Plant Cell. 2014:26(6):2285-309.

30. Glazebrook J. Contrasting mechanisms of defense against biotrophic and necrotrophic pathogens. Annu Rev Phytopathol. 2005:43(1):205-27.

31. Fang W, Xie D, Zhu H, Li W, Xu Z, Yang L, Li Z, Li S, Wang J, Nie L. Comparative proteomic analysis of Gossypium thurberi in response to Verticillium dahliae inoculation. Int J Mol Sci. 2015;16(10):25121-40.

32. Jamet E, Canut H, Boudart G, Pont-Lezica RF. Cell wall proteins: a new insight through proteomics. Trends Plant Sci. 2006;11(1):33-9.

33. Baldwin TC, Domingo C, Schindler T, Seetharaman G, Stacey N, Roberts K. DCAGP1, a secreted arabinogalactan protein, is related to a family of basic proline-rich proteins. Plant Mol Biol. 2001;45(4):421-35.

34. Hijazi M, Roujol D, Nguyen-Kim H, Del Rocio Cisneros Castillo L, Saland E, Jamet $E$, Albenne $C$. Arabinogalactan protein 31 (AGP31), a putative network-forming protein in Arabidopsis thaliana cell walls? Ann Bot. 2014; 114(6):1087-97.

35. Hijazi M, Durand J, Pichereaux C, Pont F, Jamet E, Albenne $C$ Characterization of the arabinogalactan protein 31 (AGP31) of Arabidopsis thaliana: new advances on the Hyp-O-glycosylation of the pro-rich domain. J Biol Chem. 2012;287(12):9623-32 
36. Malinovsky FG, Fangel JU, Willats WG. The role of the cell wall in plant immunity. Front Plant Sci. 2014;5:178.

37. Endler A, Persson S. Cellulose synthases and synthesis in Arabidopsis. Mol Plant. 2011;04(2):199-211.

38. Lukowitz W, Nickle TC, Meinke DW, Last RL, Conklin PL, Somerville CR. Arabidopsis cyt1 mutants are deficient in a mannose-1-phosphate guanylyltransferase and point to a requirement of $\mathrm{N}$-linked glycosylation for cellulose biosynthesis. Proc Natl Acad Sci U S A. 2001;98(5):2262-7.

39. Le RJ, Brigitte $H$, Anne C, Simon H, Godfrey N. Glycosylation is a major regulator of phenylpropanoid availability and biological activity in plants. Front Plant Sci. 2016;7:573.

40. Cosgrove DJ. Re-constructing our models of cellulose and primary cell wall assembly. Curr Opin Plant Biol. 2014;22(0):122-31.

41. Lecourieux D, Ranjeva R, Pugin A. Calcium in plant defence-signalling pathways. New Phytol. 2010;171(2):249-69.

42. Zhang X, Liu CJ. Multifaceted regulations of gateway enzyme phenylalanine ammonia-lyase in the biosynthesis of phenylpropanoids. Mol Plant. 2015;8(1):17-27.

43. Xie C, Wang C, Wang $X$, Yang $X$. Proteomics-based analysis reveals that Verticillium dahliae toxin induces cell death by modifying the synthesis of host proteins. J Gen Plant Pathol. 2013;79(5):335-45.

44. Gayoso C, Pomar F, Novo-Uzal E, Merino F, Martínez de llárduya Ó. The Ve-mediated resistance response of the tomato to Verticillium dahliae involves $\mathrm{H}_{2} \mathrm{O}_{2}$, peroxidase and lignins and drives PAL gene expression. BMC Plant Biol. 2010;10(1):1-19.

45. Kumar V, Parkhi V, Kenerley C, Rathore K. Defense-related gene expression and enzyme activities in transgenic cotton plants expressing an endochitinase gene from Trichoderma virens in response to interaction with Rhizoctonia solani. Planta. 2009;230(2):277-91.

46. Mittler R, Vanderauwera S, Suzuki N, Miller G, Tognetti VB, Vandepoele K, Gollery M, Shulaev V, Van Breusegem F. ROS signaling: the new wave? Trends Plant Sci. 2011;16(6):300-9.

47. Lamb C, Dixon RA. The oxidative burst in plant disease resistance. Annu Rev Plant Physiol Plant Mol Biol. 1997;48(1):251-75.

48. Oger E, Marino D, Guigonis J-M, Pauly N, Puppo A. Sulfenylated proteins in the Medicago truncatula-Sinorhizobium meliloti symbiosis. J Proteome. 2012; 75(13):4102-13.

49. Lescot M, Dehais P, Thijs G, Marchal K, Moreau Y, Van de Peer Y, Rouze P, Rombauts S. PlantCARE, a database of plant cis-acting regulatory elements and a portal to tools for in silico analysis of promoter sequences. Nucleic Acids Res. 2002;30(1):325-7.

50. Higo K, Ugawa Y, Iwamoto M, Korenaga T. Plant cis-acting regulatory DNA elements (PLACE) database: 1999. Nucleic Acids Res. 1999;27(1):297-300.

51. Artico S, Nardeli SM, Brilhante O, Grossi-de-Sa MF, Alves-Ferreira M. Identification and evaluation of new reference genes in Gossypium hirsutum for accurate normalization of real-time quantitative RT-PCR data. BMC Plant Biol. 2010;10:49.

52. Karimi M, De Meyer B, Hilson P. Modular cloning in plant cells. Trends Plant Sci. 2005;10(3):103-5.

53. An G. Binary Ti vectors for plant transformation and promoter analysis. Methods in Enzymol. 1987;153:292-305.

54. Sparkes IA, Runions J, Kearns A, Hawes C. Rapid, transient expression of fluorescent fusion proteins in tobacco plants and generation of stably transformed plants. Nat Protoc. 2006;1 (4):2019-25.

55. Yang J, Ji L, Wang X, Zhang Y, Wu L, Yang Y, Ma Z. Overexpression of 3-deoxy-7-phosphoheptulonate synthase gene from Gossypium hirsutum enhances Arabidopsis resistance to Verticillium wilt. Plant Cell Rep. 2015; 34(8):1429-41.

56. Clough SJ, Bent AF. Floral dip: a simplified method for Agrobacterium-mediated transformation of Arabidopsis thaliana. Plant J. 1998;16(6):735-43.

57. Jefferson RA, Kavanagh TA, Bevan MW. GUS fusions: beta-glucuronidase as a sensitive and versatile gene fusion marker in higher plants. EMBO J. 1987; 6(13):3901-7.

58. Liu Y, Schiff M, Marathe R, Dinesh-Kumar SP. Tobacco Rar1, EDS1 and NPR1/ NIM1 like genes are required for $\mathrm{N}$-mediated resistance to tobacco mosaic virus. Plant J. 2002;30(4):415-29.

59. Gao X, Britt RC Jr, Shan L, He P. Agrobacterium-mediated virus-induced gene silencing assay in cotton. J Vis Exp. 2011;54:e2938.
60. Xu F, Yang L, Zhang J, Guo X, Zhang X, Li G. Prevalence of the defoliating pathotype of Verticillium dahliae on cotton in Central China and virulence on selected cotton cultivars. J Phytopathol. 2012;160(7-8):369-76.

61. Li J, Giesy JP, Yu L, Li G, Liu C. Effects of tris(1,3-dichloro-2-propyl) phosphate (TDCPP) in Tetrahymena thermophila: targeting the ribosome. Sci Rep. 2015;5: 10562.

62. Schenk ST, Hernandez-Reyes C, Samans B, Stein E, Neumann C, Schikora M, Reichelt M, Mithofer A, Becker A, Kogel KH, et al. N-acyl-homoserine lactone primes plants for cell wall reinforcement and induces resistance to bacterial pathogens via the salicylic acid/oxylipin pathway. Plant Cell. 2014;26(6):2708-23.

63. Peer WA, Cheng Y, Murphy AS. Evidence of oxidative attenuation of auxin signalling. J Exp Bot. 2013;64(9):2629-39.

64. Rushton PJ, Torres JT, Parniske M, Wernert P, Hahlbrock K, Somssich IE. Interaction of elicitor-induced DNA-binding proteins with elicitor response elements in the promoters of parsley PR1 genes. EMBO J. 1996;15(20):5690-700.

65. Jiang Y, Duan Y, Yin J, Ye S, Zhu J, Zhang F, Lu W, Fan D, Luo K. Genomewide identification and characterization of the Populus WRKY transcription factor family and analysis of their expression in response to biotic and abiotic stresses. J Exp Bot. 2014;65(22):6629-44.
Ready to submit your research? Choose BMC and benefit from:

- fast, convenient online submission

- thorough peer review by experienced researchers in your field

- rapid publication on acceptance

- support for research data, including large and complex data types

- gold Open Access which fosters wider collaboration and increased citations

- maximum visibility for your research: over $100 \mathrm{M}$ website views per year

At BMC, research is always in progress.

Learn more biomedcentral.com/submissions 